\title{
Influence of the sea state on Mediterranean heavy precipitation: a case-study from HyMeX SOP1
}

\author{
Thévenot O. ${ }^{1,{ }^{*}}$, Bouin M.-N. ${ }^{1}$, Ducrocq V. ${ }^{2}$, Lebeaupin Brossier C. ${ }^{2}$, Nuissier O. ${ }^{2}$, Pianezze Joris ${ }^{3}$, \\ Duffourg F. ${ }^{2}$
}

${ }^{1}$ CMM/CNRM (Météo-France); Brest France

${ }^{2}$ CNRM-GAME (CNRS/Météo-France); Toulouse France

${ }^{3}$ LPO (CNRS//fremer/IRD/UBO); Plouzané France

*Corresponding author : Ophélie Thévenot, email address : ophelie.thevenot@meteo.fr

\begin{abstract}
:
Sea state can influence the turbulent air-sea exchanges, especially the momentum flux, by modifying the sea-surface roughness. The high-resolution non-hydrostatic convection-permitting model MESO-NH is used here to investigate the impact of a more realistic representation of the waves on heavy precipitation during the Intense Observation Period (IOP) 16a of the first HyMeX Special Observation Period (SOP1). Several quasi-stationary mesoscale convective systems developed over the western Mediterranean region, two of them over the sea, and resulted in heavy precipitation on the French and Italian coasts on 26 October 2012. Three different bulk parametrizations are tested in this study: a reference case (NOWAV) without any wave effect, a parametrization taking into account theoretical wave effects (WAV) and a last one with realistic wave characteristics from the MFWAM analyses (WAM). Using a realistic wave representation in WAM significantly increases the roughness length and the friction velocity with respect to NOWAV and WAV. The three MESO-NH sensitivity experiments of the IOP16a show that this surface-roughness increase in WAM generates higher momentum fluxes and directly impacts the low-level dynamics of the atmosphere, with a slowdown of the $10 \mathrm{~m}$ wind, when and where the wind speed exceeds $10 \mathrm{~m} \mathrm{~s}-1$ and the sea state differs from the idealized one. The turbulent heat fluxes are not significantly influenced by the waves, these fluxes being controlled by the moisture content rather than by the wind speed in the simulations. Although the convective activity is globally well reproduced by all the simulations, the difference in the low-level dynamics of the atmosphere influences the localization of the simulated heavy precipitation. Objective evaluation of the daily rainfall amount and of the $10 \mathrm{~m}$ wind speed against the observations confirms the positive impact of the realistic wave representation on this simulation of heavy precipitation.
\end{abstract}

Keywords : air-sea exchanges, Mediterranean Sea, HyMeX, MESO-NH, sea state, roughness length, turbulent fluxes, heavy precipitation 


\section{1. Introduction}

Regularly during the autumn, Heavy Precipitating Events (HPEs) occur over the western Mediterranean basin and more particularly the mountainous coastal regions of Spain, France and Italy. These events generate high rainfall amount in a very short time on localized areas, often leading to flash flood events with dramatic consequences on goods and people (Llasat et al. 2013). Numerical Weather Prediction (NWP) of HPEs is still challenging. Because they represent an important source of societal damages, a better understanding of the underlying mechanisms as well as an improvement of their representation by NWP models is therefore a key step towards mitigating their impact. This is one of the objectives of the 10-year programme called HyMeX (Hydrological cycle in the Mediterranean Experiment, Drobinski et al. 2014) launched in 2010 which aims at improving our understanding of the Mediterranean water cycle with a specific attention on intense weather events. In particular, a large field campaign dedicated to heavy precipitation and flash flooding (called Special Observation Period - SOP1) took place during autumn 2012 in the western Mediterranean region (Ducrocq et al 2014).

Two different meteorological situations can generate HPEs in the Mediterranean basin. On one hand large rainfall amount accumulate for several days at the same location with the slowdown of a frontal disturbance. On the other hand, heavy precipitation can be observed within a few hours over a small area where a MCS (Mesoscale Convective System) remains quasi-stationary (Nuissier et al. 2008). The second case is more favourable to flash flood events (Ducrocq et al. 2003, 2004). A combination of conducive factors is necessary to the generation of a quasi-stationary MCS at the origin of HPEs. First, a slow-evolving synoptic situation induces marine lowlevel jets advecting warm and moist air from the Mediterranean Sea to the coasts (Homar et al. 1999; Nuissier et al. 2011; Ricard et al. 2012). Conditional unstability is then released if the low-level flow is forced to lift when encountering the coastal mountains. Triggering of deep convection can also occur upwind

${ }^{\dagger}$ Prepared using the QJRMS class file, available at the mountains due to low-level convergence over the sea or due to a cold pool beneath the convective systems (Ducrocq et al. 2008).

Several studies examined the influence of the Mediterranean Sea in the generation of HPEs. Duffourg and Ducrocq (2011) who focused on the origin of the moisture feeding the precipitating systems showed that the evaporation over the Mediterranean Sea represents a major source of humidity (between 40 and 60\%) transported by the low-level jet towards the MCS. The other sources of humidity come from the Atlantic Ocean and Africa. Strong exchanges of moisture and heat between the ocean and the atmosphere are specifically achieved through the latent heat flux. Lebeaupin et al. (2006) witnessed also a strong influence of the SST (Sea Surface Temperature) variations on the atmospheric low-level dynamics for convective-scale numerical simulations of three HPEs, with an increase of latent and sensible heat fluxes for warmer SST. This directly produces an increase of the convective activity during the event with consequently more rainfall amount. The influence of the bulk parametrization of the turbulent fluxes used within the model on HPE simulations has also been shown by Lebeaupin-Brossier et al. (2008) with a comparison between the formulation of Louis (1979) and the COARE (Coupled OceanAtmosphere Response Experiment) bulk algorithm from Fairall et al. (2003). Strong differences were obtained between both parametrizations, especially regarding the momentum and latent heat fluxes with lower values of both fluxes in strong-wind conditions by the COARE parametrization. These reduced airsea exchanges led to a decrease in the moisture feeding of the convective system with lower simulated rainfall amount.

Past studies based on the analysis of in situ data have highlighted the wave influence on sea-surface exchanges through the dependence of the roughness length to the wave age (Smith et al. 1992; Drennan et al. 2003). This relationship has a direct impact on the wind stress and therefore on the near surface winds and on the low-level dynamics. A dependence between the roughness length and the wave age is included by several bulk parametrizations, among which the COARE 3.0 parametrization (Fairall et al. 2003). For operational medium-range forecasts, the European Center for Medium-range Weather Forecasts (ECMWF) has been running since 1998 a coupled system between the atmospheric and the wave modelling parts using the wind input 
term of the wave model to estimate the Charnock parameter which, in turn, determines the surface roughness (Janssen 2004). Oppositely, the approach used in the present study uses the wave parameters from the wave model as an input of the COARE 3.0 parametrization of turbulent fluxes in the atmospheric model.

This study focuses on the influence of the waves in the simulation of HPEs and more particularly in the intensity and the localization of the precipitation. It investigates the welldocumented HPEs which occurred during HyMeX SOP1 on 26 October 2012. During this event, most of the MCSs affecting the area initiated and developed at sea. This case is thus well adapted for studying the impact of the waves on the low-level jet feeding the MCS and on the precipitation forecast through the airsea fluxes parametrization. The meteorological environment and sea state encountered during this HPE are presented in details in section 2. Then, a description of how the waves are taken into account by the bulk algorithm COARE 3.0 (Fairall et al. 2003) as well as an evaluation of the sensitivity of the COARE parametrization to these wave representations are given in section 3. The numerical experiments using the convection-permitting MESO-NH model (Lafore et al. 1997) are described in section 4 and their results are discussed in section 5 before concluding remarks in section 6 .

\section{Case study: IOP16a}

\subsection{Synoptic situation}

This case study focuses on the HPEs that occurred on 26 October 2012 over the northwestern Mediterranean region, which corresponds to the Intense Observation Period (IOP) 16a of the HyMeX SOP1 (Ducrocq et al. 2014).

The upper-level synoptic meteorological situation is shown in Figure 1. It is characterized by a cut-off low centered over Portugal on 25 October, associated with a southwesterly and diffluent upper-level flow over the northwestern Mediterranean where deep convection triggered. The pressure low progressed eastward while deepening and evolved in a thalweg extended from southeastern France to Morocco on 27 October, 00 UTC.

The AROME-WMED analysis (Fourrié et al. 2015) at 2.5$\mathrm{km}$ horizontal resolution provides a description of the lowlevel atmospheric circulation over the western Mediterranean
(Fig. 2). On 25 October at 12 UTC (Fig. 2a), the low-level 117 circulation over southern Spain is associated with a low pressure 118 off Portugal. Low-level flow over sea is weak, except over the 119 western side with southwesterly to southerly flow facing the 120 Spanish coastal mountains. As the low-level pressure decreases 121 over the northwestern Mediterranean on 26 October, the low- 122 level southerly flow associated with moist and warm air reinforces 123 over the western Mediterranean. A convergence line develops 124 on the morning of 26 October between the southerly flow and 125 southwesterly colder winds (Fig. 2b). A southerly moist and warm 126 flow over the Tyrrhenian Sea from Tunisia to Gulf of Genoa 127 establishes during the morning of 26 October (Fig. 2b and 2c). $\quad 128$

\subsection{Chronology of the convective systems}

Deep convection triggers in several places during the night from 25 to 26 October and the following day as evidenced by the infrared temperature (Fig. 3). A first MCS (called hereafter MCS0) forms over the sea between the Spanish coast and the Balearic Islands around 22 UTC on 25 October. This quasistationary V-shape MCS begins to decay around 04 UTC on 26 October. Northward, new convective cells triggered near 05 UTC forming a MCS (called MCS1) over the Gulf of Lion. MCS1 splits in two MCSs (MCS1a and MCS1b). MCS1a progresses northward, with convective rainfall reaching the southwest French coast around 10 UTC. This MCS progressively decays after reaching the coast, with however orographic precipitation remaining till late afternoon over the Cévennes. In the same time, MCS1b maintains and strenghtens over the Mediterranean Sea while moving northeastward to the French coasts on the morning of 26 October. The mature system remains quasi-stationary over and offshore the southeast French coasts until 17 UTC. High hourly surface rainfall totals up to $50 \mathrm{~mm}$ are observed by the rain gauges over land. This MCS evacuates eastward and decreases after 17 UTC. Local flash flooding made two casualties in Toulon (southeast France). Meanwhile, a fourth quasi-stationary MCS (MCS2) develops on the Italian coast. It initiates near 06 UTC on 26 October and remains quasi-stationary all the morning (Fig. 3c). Both MCS1b and MCS2 lead to heavy precipitation. It must be noticed that as a large part of the MCS development occurs over the sea, larger precipitation amounts may occur over the sea as 
well. This is however not possible to confirm due to the lack of

direct measurements at sea.

\subsection{Evolution of the sea state}

The mean sea state can be described using two main characteristics of the waves: the significant wave height is the average height (trough to crest) of the highest one third of the waves, and the peak period of the waves is the period at which the waves reach their maximum of energy, given by the wave energy spectrum. During the second half of 25 October 2012, the sea state of the northwestern part of the Mediterranean is characterized by a smooth surface with significant wave height inferior to $0.5 \mathrm{~m}$ and a peak period inferior or equal to $5 \mathrm{~s}$, except south of the Balearic Islands where the significant wave height ranged between 1 and $1.3 \mathrm{~m}$ with an associated peak period between 5 and 6 s. On 26 October 2012, the sea state is globally rougher with a significant wave height around $1.5 \mathrm{~m}$ (Fig. 4c, d) except locally where it is superior to $2.5 \mathrm{~m}$ (over the Gulf of Lion and west of Sardinia). The peak period ranges between 6 and $7 \mathrm{~s}$ the whole day (Fig. 4a, b). These values are issued from the 3-hourly, 10-km resolution analysis of the regional wave forecasting model $M F W A M$ and witness a typical mixed wind sea. $M F W A M$ is a third generation ocean wave prediction model (The WAMDI Group 1988) used operationally by MétéoFrance and forced every 6 hours by the $10-\mathrm{m}$ wind of the global ARPEGE forecasting model of Météo-France at 10-km resolution. The regional $M F W A M$ analyses used in this study do not use any data assimilation, but are forced as a boundary condition by the MFWAM global model which assimilated, at the time period of the experiment, satellite altimetry data from Jason-1 and Jason-2.

Two moored buoys are deployed in the northwestern Mediterranean Sea, one in the Gulf of Lion (Lion buoy, $42.06^{\circ} \mathrm{N}$ $4.64^{\circ} \mathrm{E}$ ) and one off the southeast French coast (Azur buoy, $\left.43.38^{\circ} \mathrm{N} 7.83^{\circ} \mathrm{E}\right)$ recording hourly atmospheric and oceanic parameters (see locations in Fig. 4). The significant wave height and peak period recorded by these buoys are not assimilated in the MFWAM analyses and can thus be used to independently assess the quality of the MFWAM products at these two locations. The comparison on the IOP16a time period (from the 25 October at 12 UTC to the 27 October at 00 UTC, Fig. 5a,b) highlights an underestimation of the significant wave height by the MFWAM analysis (negative bias of $-0.18 \mathrm{~m}$ for Azur and $-0.42 \mathrm{~m}$ for Lion) but no significant bias for the peak period. The temporal variations of both parameters are well reproduced by the wave model as witnessed by the correlation coefficient superior to $85 \% \quad 199$ for each parameter. Ultimately, the scatter index gives a relative 200 uncertainty between 35 and 50\% for the wave height and 15\% for 201 the peak period so that this latter parameter is better reproduced 202 by the model.

\section{Influence of the sea state on the turbulent fluxes}

\subsection{Parametrization of the turbulent fluxes at the air-sea} interface

Different parametrizations can be used to determine the sea207 surface turbulent fluxes (i.e. momentum $\tau$, sensible $H_{s}$ and latent $H_{l}$ heat fluxes). The COARE parametrization is a commonly-used bulk parametrization for the computation of turbulent fluxes in numerical models and has already been used for the study of HPEs (Lebeaupin-Brossier et al. 2008). The reader is referred to Fairall et al. $(1996,2003)$ for a comprehensive description of the COARE algorithm which is summarized in the Appendix.

The version 3.0 of the COARE algorithm allows to take into account the waves in the computation of the turbulent fluxes. The waves, characterized by the dimensionless wave age $\chi$, modulate the roughness length $z_{0}$ defined in Eq. (A-10) and which is a 218 key parameter in the determination of the turbulent fluxes by 219 the COARE algorithm (cf. Appendix). The modulation of the 220 roughness length by the waves is accounted for through the 221 Charnock parameter $\alpha_{c h}$ which can be expressed as a function 222 of the wave age according to the formulation of Oost et al. (2002) 223 (Eq. (1))

$$
\alpha_{c h}=50 \chi^{-2.5}
$$

$$
\chi=\frac{g T_{p}}{2 \pi u_{*}}
$$

The dimensionless wave age $\chi$ depends on the friction velocity $u_{*} \quad 225$ and on the peak period of the waves $T_{p}$ only (Eq. (2)). In this study, 226 
fluxes is evaluated and compared to the default situation where the wave age is not taken into account. In the default situation without any wave impact, the formulation of the Charnock coefficient from Hare et al. (1999) is used. $\alpha_{c h}$ is set to 0.011 for wind speed below $10 \mathrm{~m} \mathrm{~s}^{-1}$, then increases linearly up to 0.018 at $18 \mathrm{~m} \mathrm{~s}^{-1}$, and remains constant for larger wind speed values. Otherwise, the formulation of Oost et al. (2002) is used with $T_{p}$ either computed empirically or obtained from an output of a wave model. In the first case, $T_{p}$ is linearly dependent of the $10-\mathrm{m}$ wind speed $U$ with $T_{p}=0.729 U$. In the second case, $T_{p}$ is given by the $M F W A M$ analysis.

\subsection{Influence of the sea state on $z_{0}$ and $u_{*}$}

Using the COARE 3.0 parametrization, a first test of the influence of the waves on $z_{0}$ during IOP16a is run through 3 experiments (NOWAV, WAV and WAM) with an improved representation of the sea state from one to another. To be consistent with the use of MFWAM analyses, all these experiments are forced by the wind field of the atmospheric model ARPEGE used to drive the wave model MFWAM. For the first experiment called NOWAV, the wave age is not taken into account for the roughness length: it corresponds to the default situation presented above. The two other experiments (WAV and WAM) consider the formulation of Oost et al. (2002) (Eq. (1) and (2)). For WAV, $T_{p}$ is given by the 10-m wind speed of ARPEGE. For WAM, $T_{p}$ is directly given by the analysis of the regional wave forecasting model MFWAM with a resolution of $0.1^{\circ}$, updated every 3 hours.

The roughness length values obtained from the COARE parametrization over the northwestern part of the Mediterranean Sea at 12 UTC on 26 October 2012 are displayed in Figure 6. Almost the same patterns of $z_{0}$ are displayed by the three experiments, although the roughness length is globally lower for WAV compared to NOWAV. On the contrary, the roughness length maxima, especially over the Gulf of Lion, can reach values 10 times higher in WAM compared to NOWAV (from $2.10^{-4}$ to $\left.1.10^{-3} \mathrm{~m}\right)$. This difference includes also more variability in $z_{0}$ coming from the variability in the MFWAM peak period. These first tests show that a more realistic description of the wave field has a stronger impact on the surface roughness than the use of an empirical formulation based on surface winds to determine the wave characteristics. This strong albeit not systematic change of the roughness length in the WAM experiment has a direct impact on the associated friction velocity. Friction velocity differences between WAV and NOWAV and between WAM and NOWAV are displayed at 09 and 12 UTC on 26 October 2012 (Fig. 7). Positive values up to $0.08 \mathrm{~m} \mathrm{~s}^{-1}$ in the friction velocity differences between WAM and NOWAV are obtained along the southeast French coasts, the Gulf of Lion and off the Spanish coasts at both time steps. The use of the MFWAM waves induces higher values of the roughness length over most of the northwestern Mediterranean and consequently a stronger friction velocity. A comparison of the values of the drag coefficient $C_{d}$ obtained using the three parametrizations in offline mode with observed atmospheric parameters at the Lion and Azur buoys is shown Fig. 8. The drag including the realistic wave effects (WAM, red dots) is significantly larger than the ones obtained with the two other simulations for wind speed superior to $6 \mathrm{~m} \mathrm{~s}^{-1}$. It is thus expected a corresponding slowdown of the near surface winds. The atmospheric simulations discussed in the following have been designed to verify this assumption and to examine the impact on the intensity and location of the convective systems.

\section{Atmospheric numerical experiments}

\subsection{The MESO-NH model}

The non-hydrostatic atmospheric French research model MESONH (Lafore et al. 1997) is used for studying the effect of the sea 291 state on the simulation of the convective precipitating systems of 292 IOP16a. The simulation domain covers an area of $750 \times 1250 \mathrm{~km}$ 293 including a large part of the western Mediterranean Sea region 294 (Fig. 9). The marine domain here represents thus more than half 295 of the full domain, in order to cover a large part of the upstream 296 zone and to evaluate the impact of an improved representation of 297 the waves on the sea-surface fluxes.

The model resolution and associated physical parametrization 299 package are the same as those used in previous studies of HPEs 300 using MESO-NH (e.g. Nuissier et al. 2008). The horizontal 301 grid has a $2.5-\mathrm{km}$ horizontal resolution. The vertical grid has 302 55 stretched levels from about $19 \mathrm{~m}$ to $21 \mathrm{~km}$ (Gal-Chen and 303 
The prognostic variables of the model are the three components of the wind, the dry potential temperature, the turbulent kinetic energy and the mixing ratios of the water vapor and of five different classes of hydrometeors (cloud water, rain water, primary ice, snow aggregates, and graupel). The evolution of the water species are governed by a bulk microphysical scheme (Caniaux et al. 1994; Pinty and Jabouille 1998). The parametrization of the turbulence is based on a 1.5-order closure (Cuxart et al. 2000). Thanks to its high horizontal resolution, the atmospheric deep convection is explicitly solved by the model.

The surface conditions and the air-surface exchanges are governed by the SURFEX surface model (Masson et al. 2013). The sea-surface turbulent fluxes parametrization is the COARE 3.0 parametrization (see section 3.2).

\subsection{Sensitivity simulations}

Three sensitivity experiments using three different configurations of the COARE parametrization are performed, using the same experimental design as in section 3.2 (Table 1).

The three companion $M E S O-N H$ simulations all start on 25 October 2012 at 12 UTC and last 36 hours. They are initialised and driven at their lateral boundaries every 3 hours by the highresolution $A R O M E-W M E D$ analysis (Fourrié et al. 2015). The SST field comes from the initial $A R O M E-W M E D$ analysis, which is built with the 2D Optimal Interpolation of in situ measurements (CANARI, Taillefer (2002)) blended with the Operational Sea Surface Temperature Ice Analysis (OSTIA, Donlon et al. (2012)). The SST remains constant during the 36-h integration.

\section{Results}

\subsection{The reference experiment NOWAV}

The ability of the NOWAV simulation in representing the IOP16a is evaluated here.

\subsubsection{Convective systems}

Convection over the northeastern Spain and offshore is simulated in NOWAV in the afternoon and late evening of 25 October. After 2130 UTC, it is organized in a MCS corresponding to the observed MCS0 over the sea between the Balearic Islands and northeastern Spain, and along the coast. MCS1 forms in the simulation at the tip of Catalonia around 03 UTC on 26 October 2012. The system then moves eastward over the Gulf of Lion (Fig. 10c), with a location that corresponds quite well to the observed one (Fig. 10a). The splitting in two MCSs is however not represented in the simulation. MCS1 moves northeastward like the observed MCS1b. When reaching the Var coast, the simulated MCS1 is less organized and intense than previously over the sea (Fig. 10d). It then moves northeastward over the French and then Italian coasts. When compared with the observed MCS1b (Fig. 10b), the simulated convective system progresses eastward too rapidly during the afternoon and progressively loses its MCS organization. A convective system, corresponding to the observed MCS2, forms in the simulation around 02 UTC on 26 October over the northwestern Italian coast between Genoa and La Spezia and stays at the same location till about 13 UTC. This system is simulated only a few tens of kilometers north of the observed MCS2 (not shown).

To sum up, the deep convection over the sea and coastal regions is globally reproduced in NOWAV. The chronology and location of MCS0 and MCS2 are well represented. The development of MCS1 over the sea is also well simulated, even though MCS1a does not appear in the simulation. Moroever, it is in advance and less organized than in the observations, where it reaches the French coast during the afternoon.

\subsubsection{0-m wind speed}

The simulated 10-m wind speed over the Mediterranean Sea 367 provides a broad picture of the low-level dynamics of the 368 atmosphere (Fig. 11). In the early morning of 26 October, the 369 Mediterranean Sea is affected by a southeasterly flow coming 370 from Sardinia and a southwesterly flow over the Balearic Islands 371 region, resulting in a convergence line (Fig. 11a). The simulated 372 MCS1 is located over the northern end of the convergence area. 373 North of the convergence line, an easterly flow resulting from the 374 deflection of the low-level flow by the Alps is simulated along 375 the French coast. At that time, 10-m wind speeds are close to 376 $10 \mathrm{~m} \mathrm{~s}^{-1}$. During the morning of 26 October (Fig. 11b), the 377 intensity of the southeasterly flow increases, with peak values 378 superior to $15 \mathrm{~m} \mathrm{~s}^{-1}$. The convergence line is thus reinforced.

68

9

370

1


Figure 12a and $12 \mathrm{~b}$ compares the 10-m wind speed from French coastal weather stations, moored buoys and ships and from the NOWAV simulation at 09 UTC (54 stations). The speed of the easterly to southeasterly flow along the coast in the Gulf of Lion is overestimated by 1.0 to $1.5 \mathrm{~m} \mathrm{~s}^{-1}$ in the simulation, probably linked to the absence of MCS1a in the simulation whereas the speed of the southeasterly flow over the Gulf of Lion is underestimated by 1.4 to $3.4 \mathrm{~m} \mathrm{~s}^{-1}$. The soutwesterly and the southeasterly flows are progresssively shifted eastward, the extent of the southeasterly flow diminishing as it is pushed against Corsica and Sardinia (Fig. 11c). In the afternoon of 26 October, as the eastward shift continues, the southeasterly flow is limited to a narrow region from Corsica to the Var region with weaker wind speeds $\left(<14 \mathrm{~m} \mathrm{~s}^{-1}\right)$ compared to the situation in the morning (Fig. 11d). It vanishes progressively and disappears after 17 UTC. Between the Italian coast and Corsica, a southerly flow prevails in the morning and the afternoon of 26 October and shifts to a southeasterly flow in the evening (after 1730 UTC). It remains below $8 \mathrm{~m} \mathrm{~s}^{-1}$ in the morning except over the Ligurian Sea where it feeds MCS2 with values around $10 \mathrm{~m} \mathrm{~s}^{-1}$ (Fig. 11b). It then strenghtens for the rest of the day with $10-\mathrm{m}$ wind speed between 10 and $15 \mathrm{~m} \mathrm{~s}^{-1}$ (Fig. 11d).

\subsubsection{Turbulent fluxes}

Latent heat flux is quite low over the western Mediterranean Sea (Fig. 13a). The largest values of latent heat flux, higher than $200 \mathrm{~W} \mathrm{~m}^{-2}$, are associated with the low-level southwesterly winds, located in the morning of 26 October between Spain and the Balearic Islands (Fig. 11). This area of moderate winds progresses eastward during the day and affects, at the end of the day, the whole western Mediterranean basin between Spain and Sardinia, south of Gulf of Lion. Dry air (relative humidity $<70 \%$ ) is associated with this southwesterly wind area (Fig. 13b) and produces the large evaporation. The strong low-level southeasterly winds (from Sardinia to Var at 12 UTC, see Fig. 11c) do not produce high latent heat fluxes as this low-level flow is nearly saturated (Fig. 13b). The high values of relative humidity prevent large evaporation to occur.

Sensible heat flux remains below $30 \mathrm{Wm}^{-2}$ (not shown) he whole time except beneath the MCSs with localized peak values of sensible heat flux between $100 \mathrm{~W} \mathrm{~m}^{-2}$ and $150 \mathrm{~W} \mathrm{~m}^{-2}$ corresponding to strong low-level cooling induced by evaporation of the falling precipitation. The low values of sensible heat fluxes can be partly explained by the weak differences between the SST and the 2-m air temperature over the domain ( 1 to $3^{\circ} \mathrm{C}$ locally).

Finally, the momentum flux remains lower than $0.2 \mathrm{~N} \mathrm{~m}^{-2}$ during the simulation, except under the main south-southeasterly flow directed towards the French coasts where the momemtum flux is stronger than $0.4 \mathrm{~N} \mathrm{~m}^{-2}$ with peak values close to $1 \mathrm{~N} \mathrm{~m}^{-2}$ between 07 and 12 UTC on 26 October (Fig. 13c).

\subsection{Sensitivity to sea state}

In the following paragraphs, we evaluate the sensitivity of the sea430 surface fluxes, of the atmospheric low-level conditions, and of the convective systems at the origin of heavy precipitation to the seastate representation.

\subsubsection{Sea surface turbulent fluxes}

The momentum flux simulated by the WAM simulation is 435 significantly larger than the NOWAV and WAV momentum fluxes between 07 and 12 UTC on 26 October, when and where the momentum flux is the strongest for the three simulations. The differences between the friction velocity simulated by WAM and NOWAV reach values close to $0.1 \mathrm{~m} \mathrm{~s}^{-1}$ in the southsoutheasterly flow area (Fig. 14a). As shown in section 3.2, the friction velocity is strongly linked to the roughness length which is clearly larger for WAM, and more particularly over the Gulf of Lion (Fig. 6). The larger roughness length in WAM influences thus directly the momentum flux. It has however no impact on the turbulent heat fluxes. In addition to the fact that the turbulent heat fluxes are globally low during the simulations, the area of the Mediterranean Sea with a strong impact of the waves on the roughness length is indeed associated with a low-level nearlysaturated air flow (Fig. 13) which limits latent heat flux variations. Also, the sensible heat fluxes are low in all the simulations (see section 5.1.3) as the SST and the 2-m temperature are very close to each other. 7 8 


\subsubsection{Low-level winds}

In response to larger momentum fluxes, the 10-m wind speed simulated with the WAM parametrization is 1 to $3 \mathrm{~m} \mathrm{~s}^{-1}$ lower than in the two other simulations (Fig. 14b). It results in a strong slowdown of the low-level moist south-southeasterly flow that feeds the convective systems. Ten-meter wind with speed higher than $10 \mathrm{~m} \mathrm{~s}^{-1}$ are particularly affected by this decrease, as already shown in section 3.2 (Fig. 8, see the drag coefficient $C_{d}$ with respect to the neutral $10-\mathrm{m}$ wind speed at the Lion and Azur buoys). The largest differences occur for wind speed above 7 $\mathrm{ms}^{-1}$, with $C_{d}$ values significantly higher when realistic wave characteristics are taken into account. On the other hand, using a theoretical peak period dependent on the 10-m wind speed only as in the WAV parametrization shows almost no difference with NOWAV whatever the wind speed. Accounting for the wave effects in the momentum flux using a realistic wave field as the one provided by the MFWAM analysis is of interest especially in areas with moderate to strong winds.

Table 2 lists the mean bias and the standard deviation of the difference (SDD) for NOWAV and WAM simulated 10-m wind speed against the observations taken every hour between 00 and 11 UTC on 26 October. The observed 10-m wind speed is obtained using a logarithmic profile from the wind speed at the height of the measurement (4 $\mathrm{m}$ for the moored buoys), and the simulated wind speed is extracted at the closest grid point of the model. The mean bias for both simulations is larger between 07 and 10 UTC, when the area is concerned by the stronger low-level southsoutheasterly winds. The mean bias for WAM is however reduced compared to NOWAV for this period, and more broadly between 03 and 10 UTC even though the reduction is not significant due to large uncertainties. The slowdown of the $10-\mathrm{m}$ winds by taking into account the wave effects thus improves the simulated winds with respect to the observations. No significant improvement is observed for the SDD between both sets of data, meaning that there is no modification of the spatial variations of the $10-\mathrm{m}$ wind speed in WAM compared to NOWAV.

\subsubsection{Precipitation}

Figure 15 displays the 24-h accumulated precipitation from the three simulations. Rain gauges show three areas of intense precipitation (more than $100 \mathrm{~mm}$ in $24 \mathrm{~h}$ ) from west to east: the

first one over the Cévennes mountains, the second one along the French Var coast and the last one along the northwestern Italian coast, associated with MCS1a, MCS1b and MCS2, respectively.

The main difference between the simulations concerns the precipitation associated with MCS1b. The maximum simulated rainfall amounts match the observations (142 mm/24h) with maximum daily precipitation of $123 \mathrm{~mm} / 24 \mathrm{~h}$ (NOWAV), 107 500 $\mathrm{mm} / 24 \mathrm{~h}(\mathrm{WAV})$ and $120 \mathrm{~mm} / 24 \mathrm{~h}(\mathrm{WAM})$. However these maxima 501 are located inland in NOWAV and WAV, whereas they are located 502 closer to the coast in WAM and in the observations. Over Italy, the maximum daily rainfall amounts are shifted northwestward compared to the observations in the three experiments. WAM performs a little better in extending the heavy precipitation area southward

The maxima of 24-h rainfall totals simulated by NOWAV, 508 WAV and WAM are close to the observed one, above $200 \mathrm{~mm}$. 509 Large precipitation amounts are simulated over the Cévennes 510 region by the three simulations. WAM produces more intense precipitation upwind the mountain range whereas NOWAV places 511 it over the northern part of the region. This behaviour is consistent with a weaker south-to-southeasterly flow feeding MCS1a and MCS1b during the morning. Indeed, based on idealized numerical simulations, Bresson et al. (2012) showed that convective precipitation upwind [respectively over] the Cévennes mountain range is favoured when the impinging feeding flow is weaker [resp. stronger].

To assess more precisely the skill of the simulations, scores 520 against rain gauge observations over the whole simulation domain 521 have been computed. The simulated daily rainfall amounts are 522 extracted at the closest grid point to the 2144 rain gauge stations. $\quad 523$ The mean bias, the SDD, and the correlation coefficient $(r)$ have 524 been computed, as well as two categorical scores: the Equitable 525 Threat Score (ETS; Schaefer, 1990) and the Hanssen and Kuipers 526 discriminant (HK; Hanssen and Kuipers, 1965). A perfect forecast 527 would give ETS and HK equal to 1, and null ETS and HK 528 indicate no skill. The mean bias is reduced in WAV and WAM 529 compared to NOWAV, and the correlation coefficient is increased 

at $95 \%$ with a two-sided hypothesis (Fisher test). NOWAV and WAM give almost the same SDD values whereas it is larger for WAV. The categorical scores for the $5 \mathrm{~mm}, 10 \mathrm{~mm}$ and 25 $\mathrm{mm}$ thresholds indicate that WAM performs better than NOWAV for all thresholds and scores. On the opposite, WAV performs slightly worse than NOWAV. The improvement in both ETS and HK scores is significant with a $95 \%$ probability. This objective evaluation confirms the better skill of the WAM expriment with respect to NOWAV in representing the precipitation.

To sum up, the main impact of the slowdown of the lowlevel flow in the WAM simulation, in better agreement with the observed 10-m winds, concerns the location of the intense precipitation. No significant impact on the amplitude of the maximum of precipitation is evidenced. This better match in location with the observed precipitation leads to globally better scores.

\section{Conclusions}

This study examines the impact of a better representation of the wave effect on the turbulent fluxes in the convectionpermitting simulation of coastal heavy precipitation. During HyMeX IOP16a, three MCSs produced heavy precipitation over the Cévennes mountains, on the southeast French coast and on the northwestern Italian coast with two of these systems forming over the Mediterranean Sea prior to reaching the coasts. A more realistic representation of the wave effect on the turbulent fluxes has been used in the COARE 3.0 parametrization (Fairall et al. 2003) with wave characteristics, namely peak period converted into wave age, coming from the 3-h MFWAM analyses at $10-\mathrm{km}$ resolution. First, the study highlights the theoretical impact of the waves on the roughness length and on the wind friction velocity using the turbulent fluxes parametrization alone. Comparison of the roughness length $z_{0}$ and of the friction velocity $u_{*}$ show a strong increase of both parameters when realistic wave parameters and the formulation of Oost et al. (2002) are used.

In a second set of experiments, three numerical simulations of IOP16a using the non-hydrostatic atmospheric model MESO$\mathrm{NH}$ at $2.5-\mathrm{km}$ resolution were performed using the same discrimination in the turbulent fluxes parametrization. The

impacts the low-level dynamics of the atmosphere when and where the wind speed is higher than $10 \mathrm{~m} \mathrm{~s}^{-1}$ and the sea surface state is significantly different from the idealized one. It results in 575 a significant slowdown of the 10-m wind in WAM compared to the two other simulations, due to higher momentum flux. Before and during the event, the highest latent heat exchanges at the air-sea interface correspond to areas where the low-level flow is not saturated in humidity, and not to the low-level wind maxima. As such, they are almost not sensitive to the wave representation in the fluxes parametrization. Although the convective activity is globally well reproduced by the three simulations, the difference in the low-level dynamics influences the localization of the simulated daily precipitation. The objective evaluation against the observations over the entire simulated domain for the daily rainfall amounts and along the French coast for the 10-m wind speed confirms a better representation of both parameters by the WAM simulation. The case study of IOP16a is thus sensitive to a more realistic representation of the waves with a better representation of the simulated precipitation especially due to a better representation of the low-level moist jet feeding the French coastal precipitating systems.

This study shows that, even in a moderate-wind context, the sea-surface roughness due to waves can significantly influence the low-level flow and the marine atmospheric boundary layer dynamics. As location and intensity of heavy precipitation have been shown to be very sensitive to the characteristics of the moist low-level inflow, a more realistic representation of the wave influence on the turbulent fluxes modifies the simulated precipitation. It demonstrates that wind-wave interaction is also important in convection-permitting NWP models. Large impacts may notably concern strong-wind events like mistral, midlatitude storms, tropical storms and cyclones. Therefore, the use of a simplistic wind-waves transfer function such as in WAV is in some cases not sufficient to represent the variability of the sea-surface roughness and momentum flux due to the sea state.

The perspectives of this study include different steps. First, 608 we plan the study of a second HPE (HyMeX IOP13) during which heat transfers between the ocean and the atmosphere 609 
of the simulated heat fluxes to the waves and sea-roughness representation should be higher. The surface wind speeds are higher and one can expect a stronger impact on the atmospheric surface layer and on the HPE chronology. Then, a two-way coupling between the atmospheric and wave models could be considered in a second step. The effect of a full coupling between atmospheric and wave models should be reduced with respect to the effect of a forcing as used in the present study. Indeed, the slowdown of the low-level wind obtained with the WAM configuration should partly damp the sea state and reduce the surface roughness, with a possible negative feedback on the atmosphere. Finally, it could be of interest to distinguish the total sea-state effect as taken into account in this study (the peak period may correspond in some cases to swell) from the pure windsea effect. The parametrization of Oost et al. (2002) used here corresponds to the instantaneous wind-wave equilibrium and is supposed to be constrained by the characteristics of the wind sea only.

\section{Acknowledgements}

This work is a contribution to the MISTRALS/HyMeX programme. The authors would like to acknowledge Météo-France, the ANR-2012-BS06-003 ASICS-Med, S. Belamari (CNRMGAME), L. Aouf and the PREVI/MAR team for providing the MFWAM analyses, the CNRM/CMM for maintaining the buoys and supplying the data, the HyMeX database teams (ESPRI/IPSL and SEDOO/Observatoire Midi-Pyrénées) for their help in accessing the data. We also thank S. Faroux and P. Le Moigne (CNRMGAME) for their help with the SURFEX model and G. Delautier and C. Lac (CNRM-GAME) for their help with the MESO-NH model.

\section{Appendix - Bulk parametrization of turbulent fluxes}

Bulk parametrizations of turbulent fluxes relate the latter to the vertical gradients between atmospheric and oceanic parameters close to the surface, using linear transfer coefficients $C_{d}, C_{h}$, $C_{q}$ for $\tau, H_{s}, H_{l}$ respectively. According to the Monin-Obukhov (MO) similarity theory, the turbulent fluxes can also be defined thanks to the scale parameters $u_{*}, \theta_{*}, q_{*}$ of wind, potential temperature and humidity, respectively:

$$
\tau=\rho C_{d}(\triangle U)^{2}=\rho u_{*}^{2}
$$

$$
H_{s}=\rho c_{p} C_{h} \triangle U \triangle \theta=\rho c_{p} u_{*} \theta_{*}
$$

$$
H_{l}=\rho L_{v} C_{q} \triangle U \triangle q=\rho L_{v} u_{*} q_{*}
$$

where $\triangle U, \triangle \theta, \triangle q$ are the air-sea gradients of velocity, 650 potential temperature and specific humidity close to the interface. 651 $C_{p}$ is the air heat capacity, $L_{v}$ is the vaporization heat constant 652 and $\rho$ is the air density.

In the COARE parametrization, the transfer coefficients are determined after iterations over the MO scale parameters, the 655 roughness length $z_{0}$, and the MO length $L$ using Eq. (A-6) to 656 (A-10). The stability functions $\psi_{u}, \psi_{\theta}$, and $\psi_{q}$ used in Eq. (A-6) 657 to (A-8) correspond to the generalization of atmospheric profiles 658 in neutral conditions to non-neutral conditions and depend only 659 on the stability parameter $\zeta=z / L, z$ being the reference height. $\quad 660$

$$
\begin{gathered}
u_{*}=\frac{k \Delta U}{\ln \left(\frac{z}{z_{0}}\right)-\psi_{u}(\zeta)} \\
\theta_{*}=\frac{k \Delta \theta}{\ln \left(\frac{z}{z_{0}}\right)-\psi_{\theta}(\zeta)} \\
q_{*}=\frac{k \Delta q}{\ln \left(\frac{z}{z_{0}}\right)-\psi_{q}(\zeta)}
\end{gathered}
$$

$$
L=\frac{T u_{*}^{2}(1+a q)}{\theta_{*}(1+a q)+a q_{*} T} \text { is the MO scale height }
$$

with $a \approx 0.61$ and $k=0.4$ is the constant of von Karman

$$
z_{0}=\alpha_{c h} \frac{u_{*}^{2}}{g}+0.11 \frac{\nu}{u_{*}}
$$

$\alpha_{c h}$ is the Charnock parameter (see below) and $\nu$ is the 661 kinematic viscosity of dry air. 
$z_{0}$ is obtained from Eq. (A-10) and the stability parameter $\zeta=$ $z / L$ from Eq. (A-9). Both parameters are then used to reassess $u_{*}, \theta_{*}, q_{*}$ following Eq. (A-6) to (A-8). The whole process is reiterated up to three times if the stability parameter $\zeta \leqslant 50$, else the computation is ended and the scale parameters are no more modified. At the end, the transfer coefficients and the turbulent fluxes are determined using the last iterated values of $u_{*}, \theta_{*}, q_{*}$ according to Eq. (A-3), (A-4), (A-5).

\section{References}

Bresson E, Ducrocq V, Nuissier O, Ricard D, de Saint-Aubin C. 2012 Idealized numerical study of Southern France Heavy Precipitating Events: identification of favouring ingredients. Q.J.R. Meteorol. Soc. 138: 17511763.

Caniaux G, Redelsperger JL, Lafore JP. 1994. A numerical study of the stratiform region of a fast-moving squall line. Part I: General description and water and heat budgets. J.Atmos.Sci. 51(14): 2046-2074, doi:http: //dx.doi.org/10.1175/1520-0469(1994)051〈2046:ANSOTS〉2.0.CO;2.

Cuxart J, Bougeault P, Redelsperger JL. 2000. A turbulence scheme allowing for mesoscale and large-eddy simulations. Q.J.R. Meteorol. Soc. 126(562): 1-30, doi:10.1002/qj.49712656202.

Donlon CJ, Martin M, Stark JD, Roberts-Jones J, Fiedler E, Wimmer W. 2012. The Operational Sea Surface Temperature and Sea Ice Analysis (OSTIA) system. Remote Sens. Environ. 116: 140-158, doi:10.1016/j.rse.2010.10. 0172011

Drennan WM, Graber HC, Hauser D, Quentin C. 2003. On the wave age dependence of wind stress over pure wind seas. J. Geophys. Res.: Oceans 108(C3): 8062, doi:10.1029/2000JC000715.

Drobinski P, Ducrocq V, Alpert P, Anagnostou E, Béranger K, Borga M, Braud I, Chanzy A, Davolio S, Delrieu G, Estournel C, Filali Boubrahmi N, Font J, Grubisic V, Gualdi S, Homar V, Ivanan-Picek B, Kottmeier C, Kotroni V, Lagouvardos K, Lionello P, Llasat MC, Ludwig W, Lutoff C, Mariotti A, Richard E, Romero R, Rotunno R, Roussot O, Ruin I, Somot S, TaupierLetage I, Tintoré J, Uijlenhoet R, Wernli H. 2014. HyMeX: A 10-Year Multidisciplinary Program on the Mediterranean Water Cycle. Bull. Amer. Meteor. Soc. 95(7): 1063-1082, doi:10.1175/BAMS-D-12-00242.1.

Ducrocq V, Aullo G, Santurette P. 2003. Les précipitations intenses et les inondations des 12 et 13 novembre 1999 sur le sud de la France. La Météorologie 42: 18-23.

Ducrocq V, Braud I, Davolio S, Ferretti R, Flamant C, Jansa A, Kalthoff N, Richard E Taupier-Letage I, Ayral PA, Belamari S, Berne A, Borga M, Boudevillain B, Bock O, Boichard JL, Bouin MN, Bousquet O Bouvier C, Chiggiato J, Cimini D, Corsmeier U, Coppola L, Cocquerez P, Defer E, Delano J, Di Girolamo P, Doerenbecher A, Drobinski P, Dufournet Y, Fourrié N, Gourley JJ, Labatut L, Lambert D, Le Coz J, Marzano FS, Molinié G, Montani A, Nord G, Nuret M, Ramage K, Rison B, Roussot O,
Said F, Schwarzenboeck A, Testor P, Van Baelen J, Vincendon B, Aran M, Tamayo J. 2014. HyMeX-SOP1: The Field Campaign Dedicated to Heavy Precipitation and Flash Flooding in the Northwestern Mediterranean. Bull. Amer. Meteor. Soc. 95: 1083-1100, doi:10.1175/BAMS-D-12-00244.1.

Ducrocq V, Lebeaupin C, Thouvenin T, Giordani H. 2004. L'évènement des 89 septembre 2002: situation météorologique et simulation à méso-échelle. La Houille Blanche 6: 86-92.

Ducrocq V, Nuissier O, Ricard D. 2008. A numerical study of three catastrophic precipitating events over Southern France. Part II: Mesoscale triggering and stationarity factors. Q.J.R. Meteorol. Soc. 134(630): 131145, doi:10.1002/qj.199.

Duffourg F, Ducrocq V. 2011. Origin of the moisture feeding the Heavy Precipitating Systems over Southeastern France. Nat. Hazards and Earth Syst. Sci. 11(4): 1163-1178, doi:10.5194/nhess-11-1163-2011.

Fairall CW, Bradley EF, Hare JE, Grachev AA, Edson JB. 2003. Bulk Parameterization of Air-Sea Fluxes: Updates and Verification for the COARE Algorithm. J. Climate 16(4): 571-591.

Fairall CW, Bradley EF, Rogers DP, Edson JB, Young GS. 1996. Bulk parameterization of air-sea fluxes for Tropical Ocean-Global Atmosphere Coupled-0cean Atmosphere Response Experiment. J. Geophys. Res.: Oceans 101(C2): 3747-3764.

Fourrié N, Bresson E, Nuret M, Jany C, Brousseau P, Doerenbecher A, Kreitz M, Nuissier O, Sevault E, Bénichou H, Amodei M, Pouponneau F. 2015. AROME-WMED, a real-time mesoscale model designed for the HyMeX Special Observation Periods. Geoscientific Model Development 8(7): 19191941, doi:10.5194/gmd-8-1919-2015.

Gal-Chen T, Somerville RCJ. 1975. On the use of a coordinate transformation for the solution of the Navier-Stokes equations. J. Comput. Phys. 17: 209228, doi:10.1016/0021-9991(75)90037-6.

Hare JE, Persson POG, Fairall CW, Edson JB. 1999. Behavior of Charnock's relationship for high wind conditions. In: 13th Symp. on Boundary Layers and Turbulence, Amer. Meteor. Soc. Dallas, TX, pp. 252-255.

Homar V, Ramis C, Romero R, Alonso S, García-Moya JA, Alarcón M. 1999. A Case of Convection Development over the Western Mediterranean Sea: A Study through Numerical Simulations. Meteorol. Atmos. Phys. 71(3-4): 169-188, doi:10.1007/s007030050054.

Janssen PAEM. 2004. The interaction of ocean waves and wind. Cambridge University Press, London.

Lafore JP, Stein J, Asencio N, Bougeault P, Ducrocq V, Duron J, Fischer C, Héreil P, Mascart P, Masson V, Pinty JP, Redelsperger JL, Richard E, Vilà-Guerau de Arellano J. 1997. The Meso-NH Atmospheric Simulation System. Part I: adiabatic formulation and control simulations. Annales Geophysicae 16(1): 90-109, doi:10.1007/s00585-997-0090-6.

Lebeaupin C, Ducrocq V, Giordani H. 2006. Sensitivity of torrential rain events to the sea surface temperature based on high-resolution numerical forecasts. J. Geophys. Res.: Atmospheres 111(D12110): 2156-2202, doi: 10.1029/2005JD006541. 
Lebeaupin-Brossier C, Ducrocq V, Giordani H. 2008. Sensitivity of three Mediterranean heavy rain events to two different sea surface fluxes parameterizations in high-resolution numerical modeling. J. Geophys. Res.: Atmospheres 113(D21109): 2156-2202, doi:10.1029/2007JD009613.

Llasat MC, Llasat-Botija M, Petrucci O, Pasqua AA, Rossell J, Vinet F, Boissier L. 2013. Towards a database on societal impact of Mediterranean floods within the framework of the HyMeX project. Nat. Hazards and Earth Syst. Sci. 13(5): 1337-1350, doi:10.5194/nhess-13-1337-2013.

Louis JF. 1979. A parametric model of vertical eddy fluxes in the atmosphere. Boundary-Layer Meteorology 17: 187-202.

Masson V, Le Moigne P, Martin E, Faroux S, Alias A, Alkama R, Belamari S, Barbu A, Boone A, Bouyssel F, Brousseau P, Brun E, Calvet JC, Carrer D, Decharme B, Delire C, Donier S, Essaouini K, Gibelin AL, Giordani H, Habets F, Jidane M, Kerdraon G, Kourzeneva E, Lafaysse M, Lafont S, Lebeaupin-Brossier C, Lemonsu A, Mahfouf JF, Marguinaud P, Mokhtari M, Morin S, Pigeon G, Salgado R, Seity Y, Taillefer F, Tanguy G, Tulet P, Vincendon B, Vionnet V, Voldoire A. 2013. The SURFEXv7.2 land and ocean surface platform for coupled or offline simulation of Earth surface variables and fluxes. Geoscientific Model Development 6(4): 929-960, doi: 10.5194/gmd-6-929-2013.

Nuissier O, Ducrocq V, Ricard D. 2008. A numerical study of three catastrophic precipitating events over Southern France. Part I: Numerical framework and synoptic ingredients. Q.J.R. Meteorol. Soc. 134(630): 111130, doi:10.1002/qj.200.

Nuissier O, Joly B, Joly A, Ducrocq V, Arbogast P. 2011. A statistical downscaling to identify the Large-Scale Circulation patterns associated with Heavy Precipitation Events over Southern France. Q.J.R. Meteorol. Soc. 137(660): 1812-1827, doi:10.1002/qj.866.

Oost WA, Komen GJ, Jacobs CMJ, Van Oort C. 2002. New evidence for a relation between wind stress and wave age from measurements during ASGAMAGE. Boundary-Layer Meteorology 103(3): 409-438, doi: 10.1023/A:1014913624535.

Pinty JP, Jabouille P. 1998. A mixed-phased cloud parametrization for use in a mesoscale non-hydrostatic model: Simulations of a squall line and of orographic precipitation. In: Proc. of the Conference on Cloud Physics. Amer. Meteorol. Soc: Boston: Everett, WA, USA, 17-21 Aug. 1998, pp. $217-220$.

Ricard D, Ducrocq V, Auger L. 2012. A climatology of mesoscale environment associated with Mediterranean Heavy Precipitating Events over a Northwestern Mediterranean area. J. Appl. Meteorol. Clim. .

Smith SD, Anderson RJ, Oost WA, Kraan C, Maat N, De Cosmo J, Katsaros KB, Davidson KL, Bumke K, Chadwick HM. 1992. Sea surface wind stress and drag coefficients: The HEXOS results. Boundary-Layer Meteorology 60(1-2): 109-142, doi:10.1007/BF00122064.

Taillefer F. 2002. CANARI Technical Documentation Based on ARPEGE cycle CY25T1 (AL25T1 for ALADIN), available at http://www.cnrm.meteo.fr/aladin/. Technical report.
The WAMDI Group. 1988. The WAM Model - A Third Generation Ocean 803 Wave Prediction Model. J. Phys. Oceanogr. 18(12): 1775-1810. 


\begin{tabular}{|c|c|c|}
\hline \multicolumn{3}{|c|}{$M E S O-N H$} \\
\hline \multicolumn{3}{|c|}{ Initial time: 25 October 2012, 12 UTC } \\
\hline \multicolumn{3}{|c|}{ Duration: $36 \mathrm{~h}$} \\
\hline \multicolumn{3}{|c|}{ Initial and boundary conditions: $A R O M E-W M E D$ analysis } \\
\hline \multicolumn{3}{|c|}{ Sea surface turb. flux param.: COARE 3.0} \\
\hline Name & $\alpha_{c h}$ & Wave $\left(T_{p}\right)$ \\
\hline NOWAV & Hare et al. (1999) & None \\
\hline & $0.011 \leq \alpha_{c h} \leq 0.018$ & \\
\hline WAV & Oost et al. (2002) & $T_{p}=0.729 U$ \\
\hline WAM & Oost et al. (2002) & MFWAM 3-hourly analysis \\
\hline
\end{tabular}

Table 1. Description of the three MESO-NH experiments.

\begin{tabular}{|c|c|c|c|c|}
\hline & \multicolumn{2}{|c|}{ NOWAV-Obs } & \multicolumn{2}{c|}{ WAM-Obs } \\
UTC & Mean bias & SDD & Mean bias & SDD \\
\hline $\mathbf{0 0}$ & -0.06 & 1.78 & -0.08 & 1.98 \\
\hline $\mathbf{0 1}$ & -0.03 & 1.96 & 0.06 & 1.97 \\
\hline $\mathbf{0 2}$ & 0.19 & 2.27 & 0.20 & 2.18 \\
\hline $\mathbf{0 3}$ & -0.13 & 2.45 & -0.10 & 2.74 \\
\hline $\mathbf{0 4}$ & 0.82 & 2.30 & 0.60 & 2.04 \\
\hline $\mathbf{0 5}$ & 0.27 & 2.23 & 0 & 1.98 \\
\hline $\mathbf{0 6}$ & 0.67 & 2.08 & 0.66 & 2.12 \\
\hline $\mathbf{0 7}$ & 1.01 & 2.32 & 0.81 & 2.54 \\
\hline $\mathbf{0 8}$ & 1.47 & 2.32 & 1.28 & 2.40 \\
\hline $\mathbf{0 9}$ & 1.26 & 2.73 & 0.84 & 2.87 \\
\hline $\mathbf{1 0}$ & 1.39 & 3.27 & 1.32 & 3.02 \\
\hline $\mathbf{1 1}$ & 0.84 & 3.12 & 1.0 & 3.15 \\
\hline
\end{tabular}

Table 2. Ten-meter wind speed statistical analysis $\left(\mathrm{m} \mathrm{s}^{-1}\right) ; \mathrm{SDD}=$ standard deviation of the difference.

\begin{tabular}{|c|c|c|c|c|}
\hline & & NOWAV & WAV & WAM \\
\hline & Mean bias & 2.96 & 2.77 & 2.24 \\
\hline & SDD & 22.21 & 24.47 & 22.30 \\
\hline & Correlation & 0.577 & 0.591 & 0.589 \\
\hline $\mathbf{5} \mathbf{~ m m}$ & ETS & 0.296 & 0.286 & 0.321 \\
\hline & HK & 0.496 & 0.473 & 0.522 \\
\hline $\mathbf{1 0} \mathbf{~ m m}$ & ETS & 0.245 & 0.240 & 0.281 \\
\hline & HK & 0.441 & 0.441 & 0.491 \\
\hline $\mathbf{2 5} \mathbf{~} \mathbf{m}$ & ETS & 0.210 & 0.191 & 0.229 \\
\hline & HK & 0.338 & 0.319 & 0.369 \\
\hline
\end{tabular}




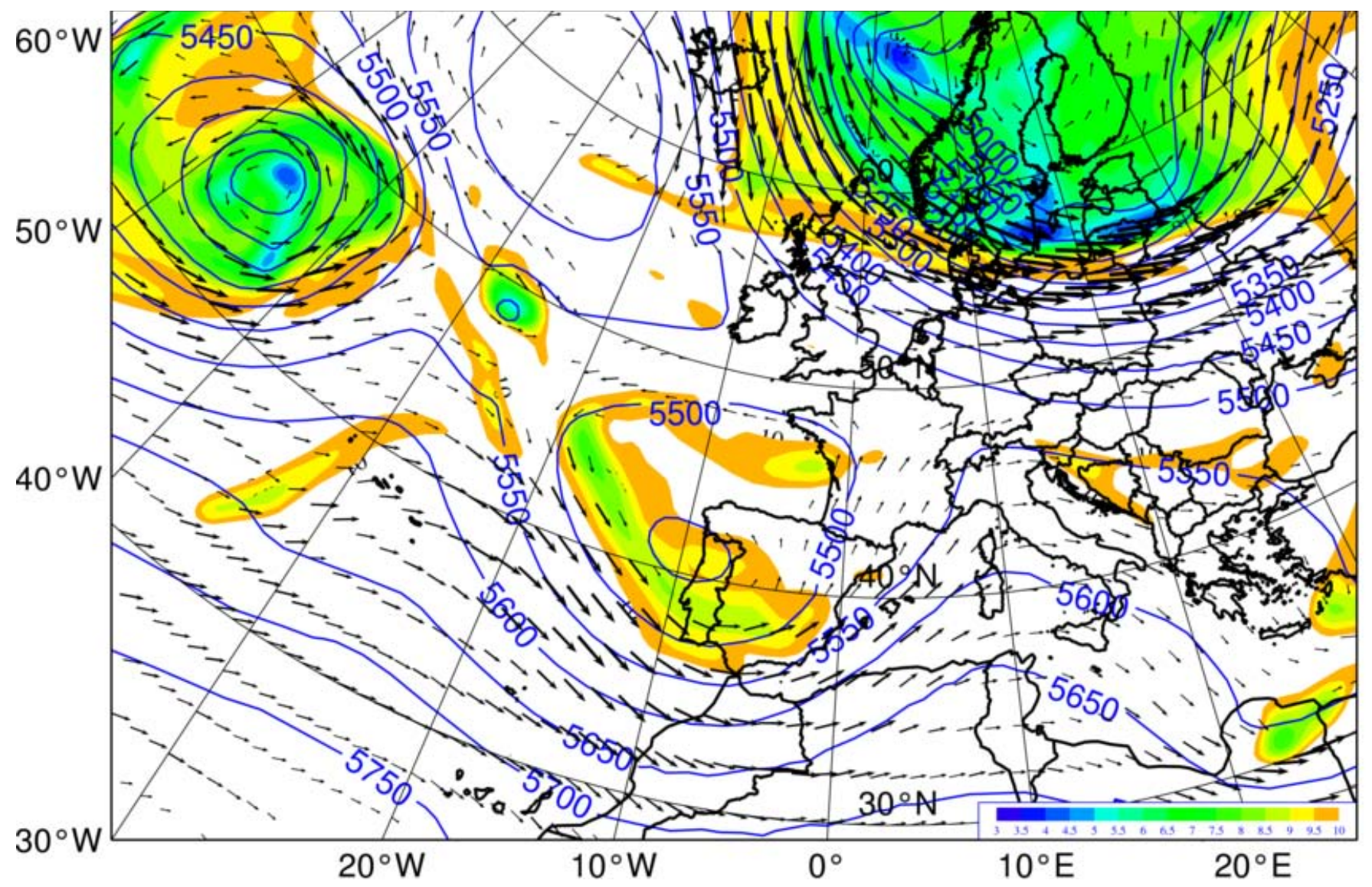

Figure 1. ARPEGE analysis at 00UTC, 26 October 2012: geopotential at $500 \mathrm{hPa}$ (isolines, $\mathrm{m}$ ), height of the $2 \mathrm{PVU}$ iso surface (colour) and wind vectors at $300 \mathrm{hPa}$ (above $10 \mathrm{~m} \mathrm{~s}^{-1}$ ). 


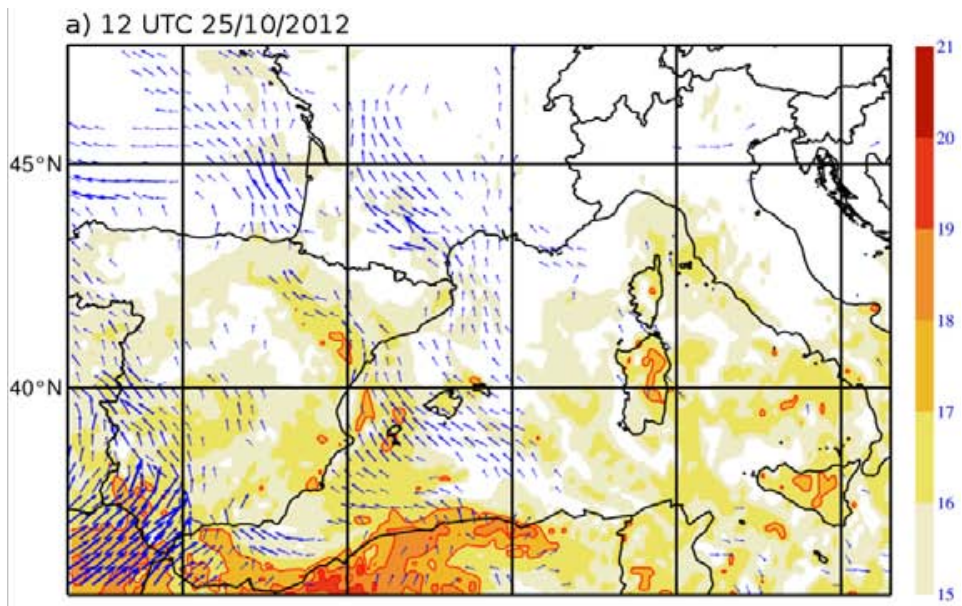

b) 06 UTC $26 / 10 / 2012$
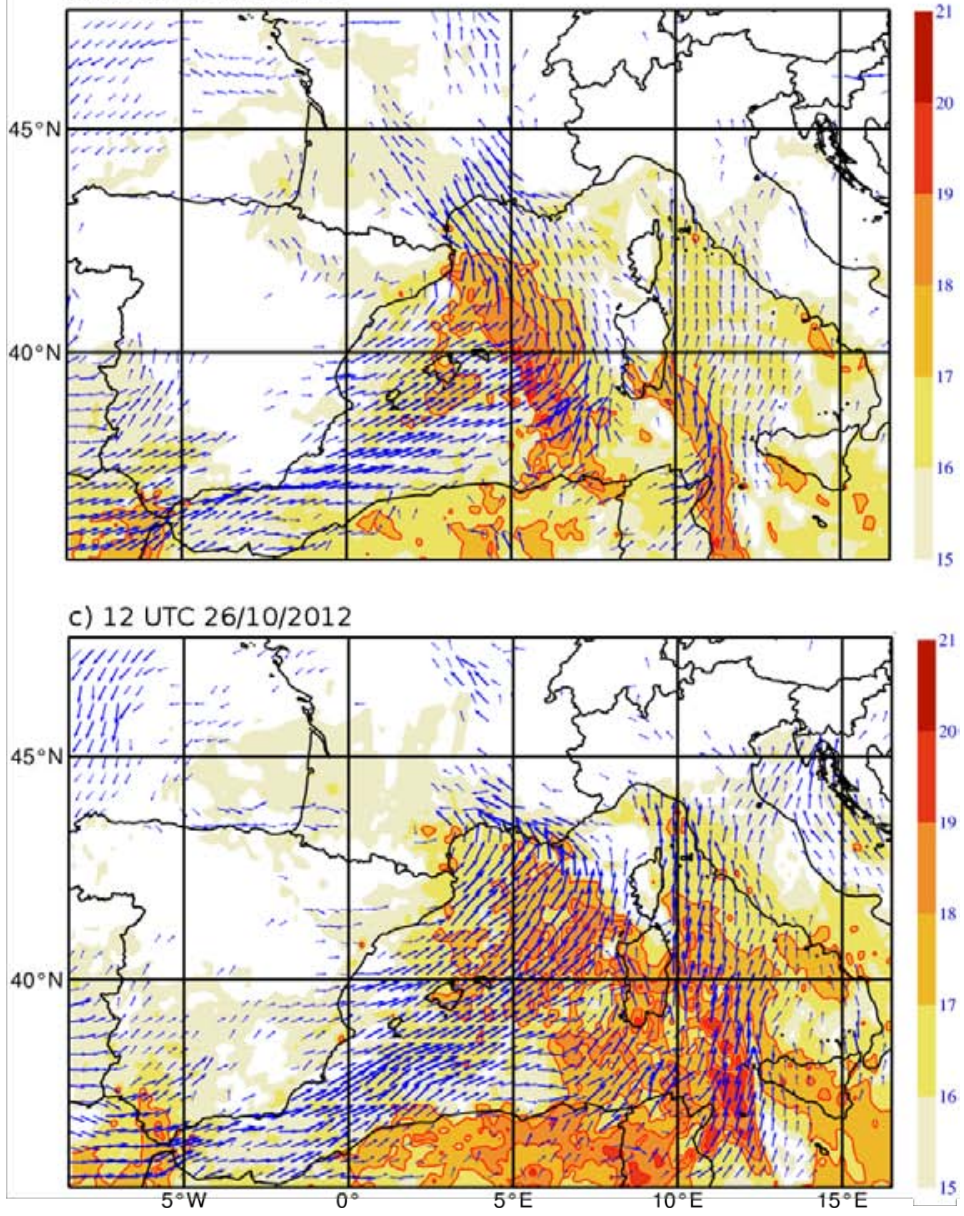

Figure 2. Wind vectors and wet bulb potential temperature at $925 \mathrm{hPa}$ at $12 \mathrm{UTC}$ on 25 October 2012 (a) and at 06 and 12 UTC on 26 October 2012 (b and c) from AROME-WMED analysis (Fourrié et al. 2015). 
a) 03 UTC

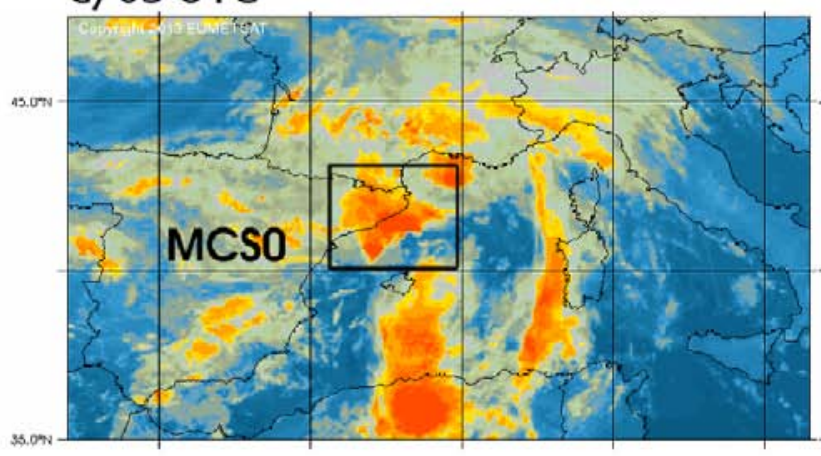

\section{c) 09 UTC}

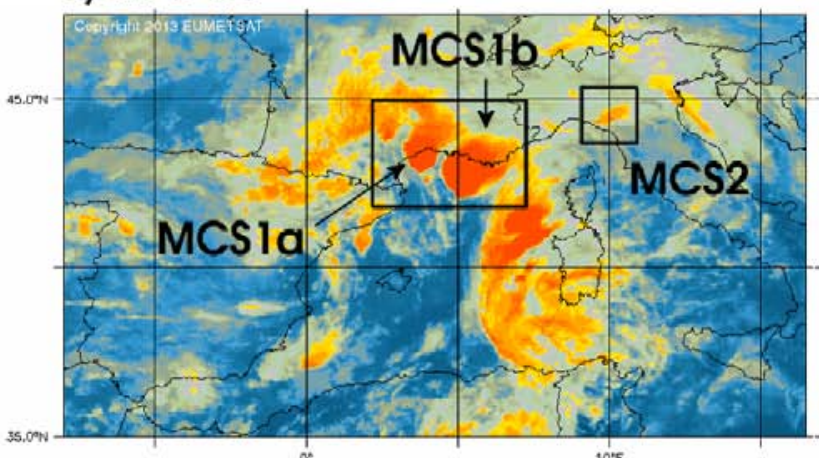

b) 06 UTC

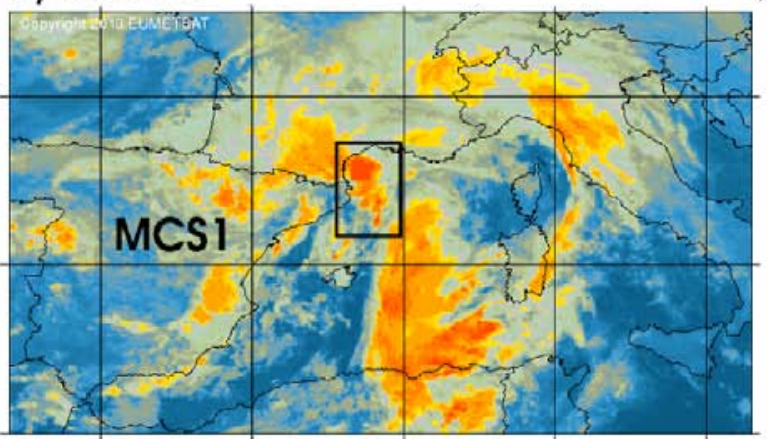

d) 14 UTC

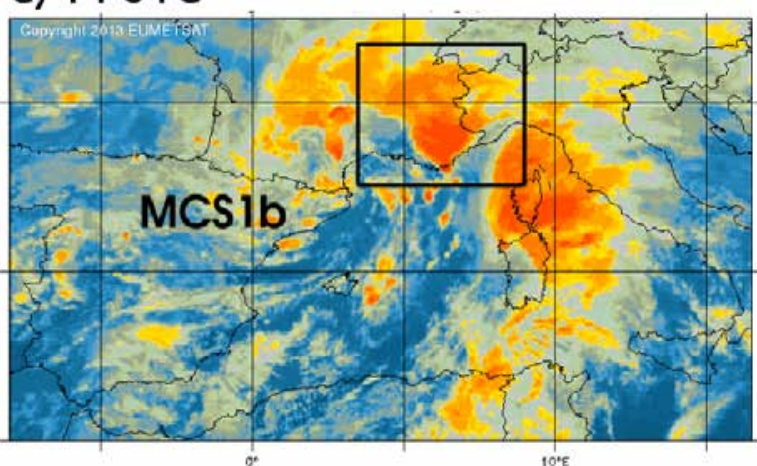

$(\operatorname{deg} C)$

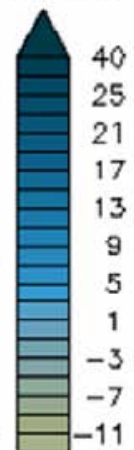

$-15$

$-19$

$-23$

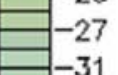

$-35$

$-39$

$-43$

-47
-53

$-57$

$-80$

Figure 3. Météosat Second Generation infrared brightness temperature $\left({ }^{\circ} \mathrm{C}\right)$ on 26 October 2012 at 03 (a), 06 (b), 09 (c), 14 (d) UTC.

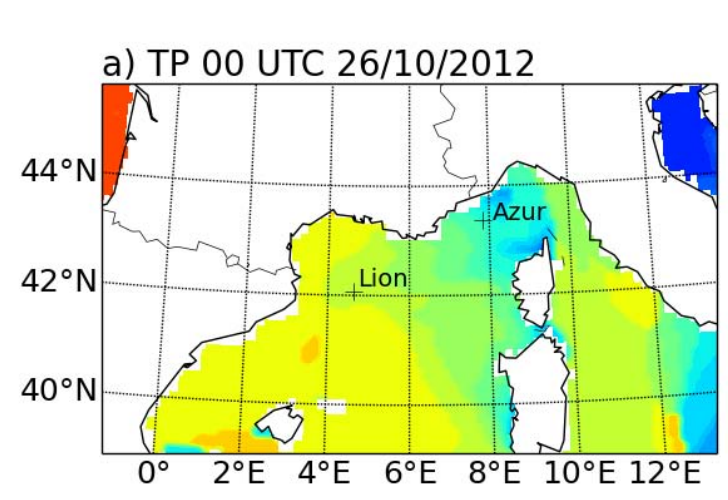

[s]

c) SWH 00 UTC $26 / 10 / 2012$

[m]
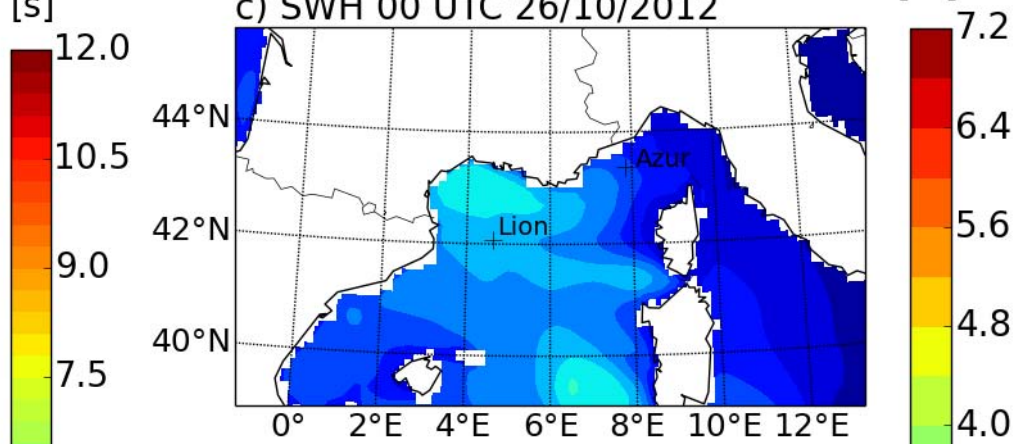

6.4

5.6

4.8

$-4.0$

6.0

b) TP 12 UTC 26/10/2012
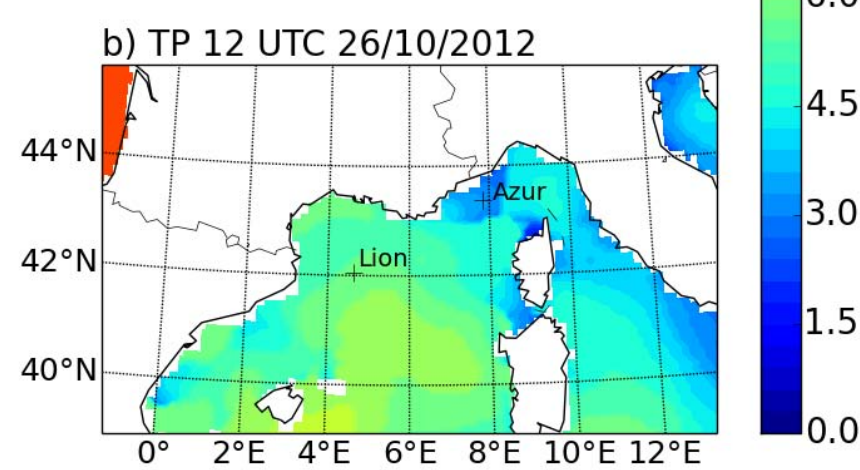

d) SWH 12 UTC 26/10/2012

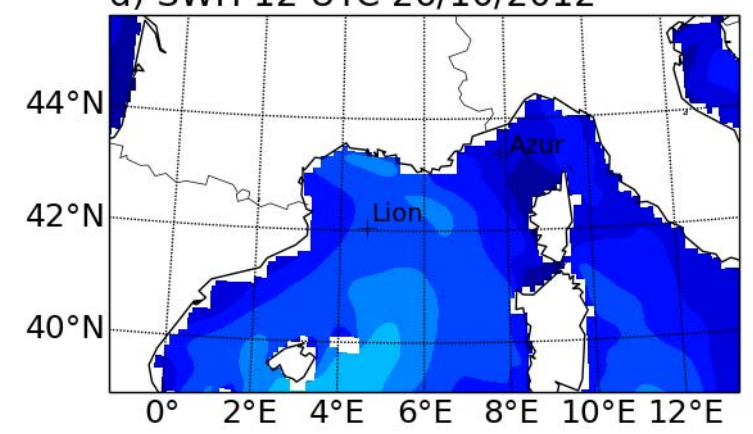




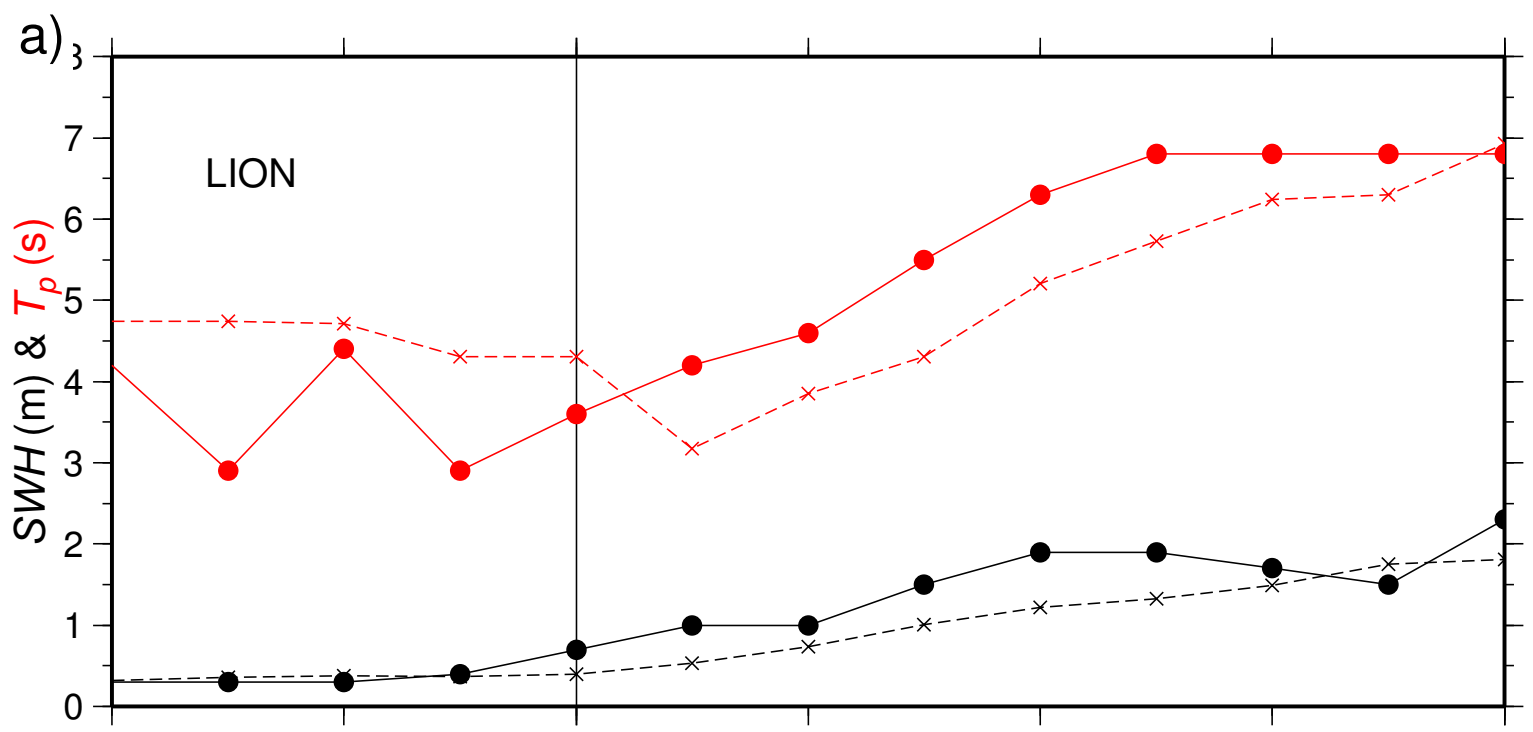

b)

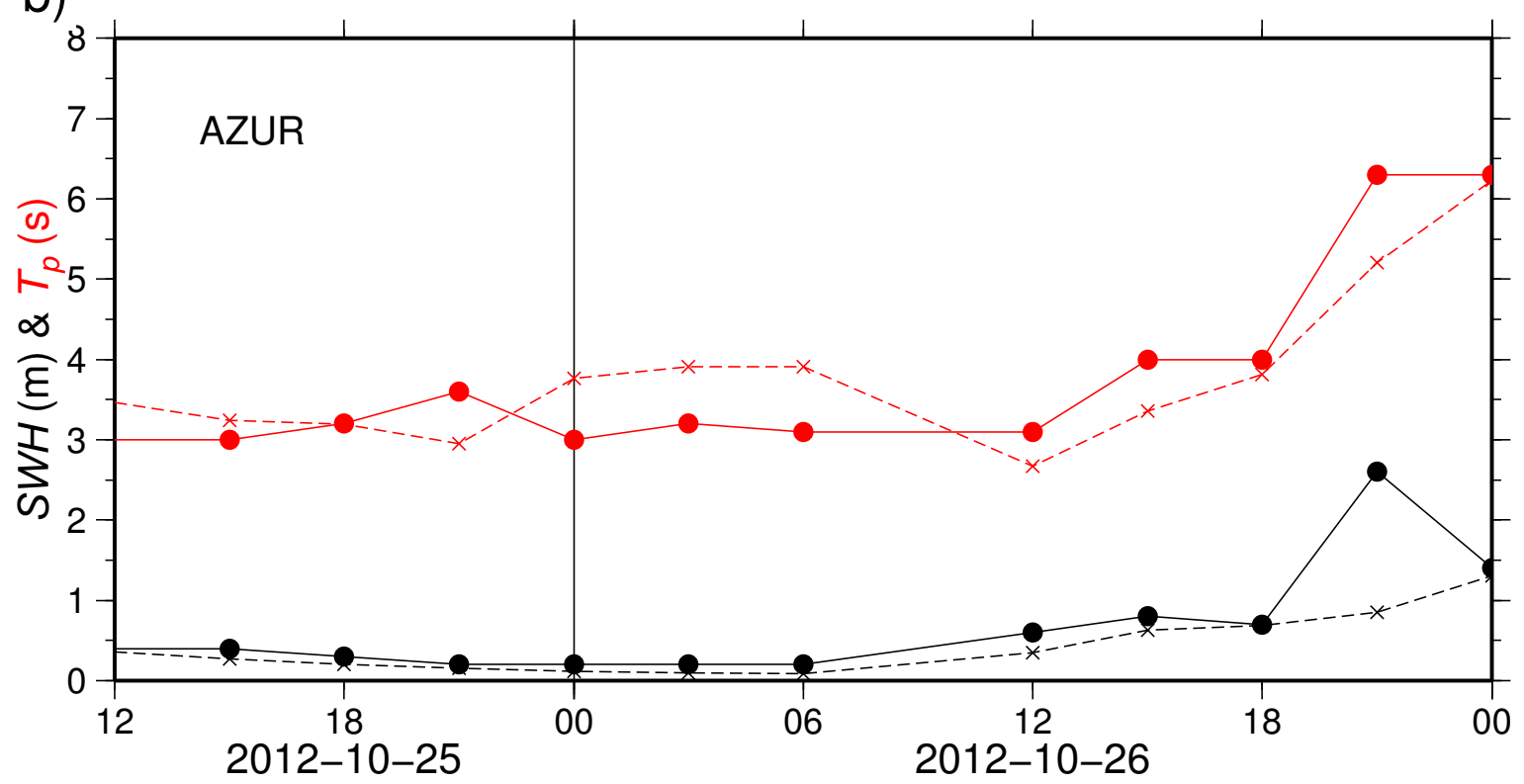

Figure 5. Time series of the wave significant height ( $S W H$, m, black) and of the peak period ( $T_{p}, \mathrm{~s}$, red) observed (solid line and dots) and modeled by $M F W A M$ (dashed line, crosses) at (a) the Lion buoy, and (b) the Azur buoy, for the time of the simulation. 


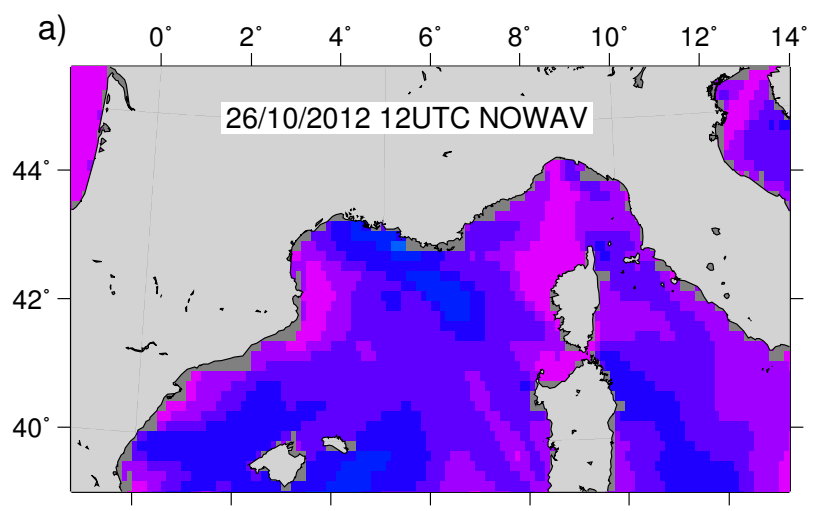

b)
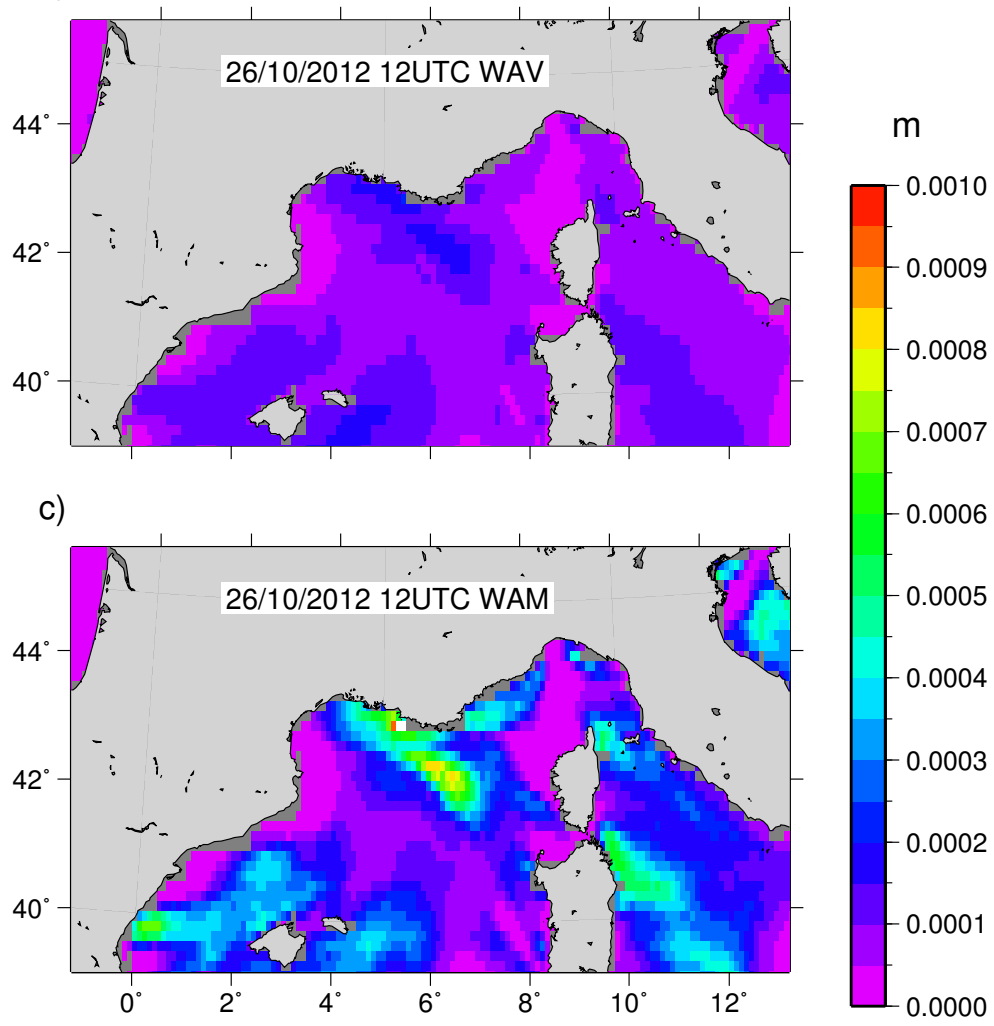

Figure 6. Roughness length $\left(z_{0}, \mathrm{~m}\right)$ for (a) NOWAV, (b) WAV and (c) WAM at 12 UTC on 26 October 2012. 


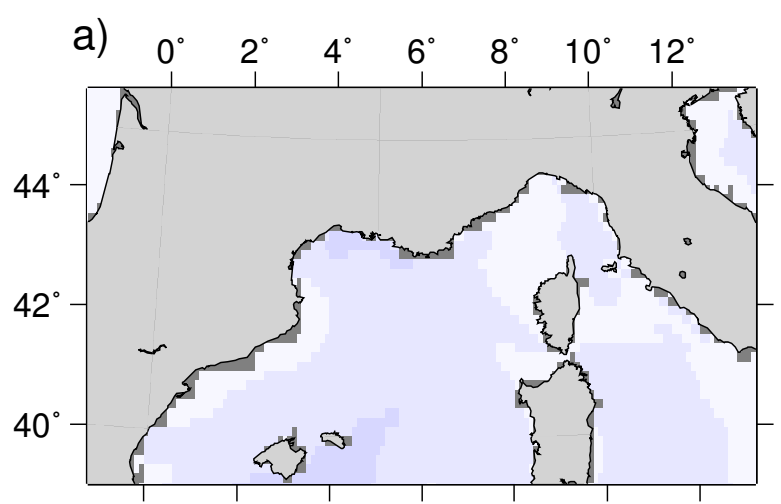

b) $0^{\circ} \quad 2^{\circ} \quad 4^{\circ} \quad 6^{\circ} \quad 8^{\circ} \quad 10^{\circ} 12^{\circ}$

C)
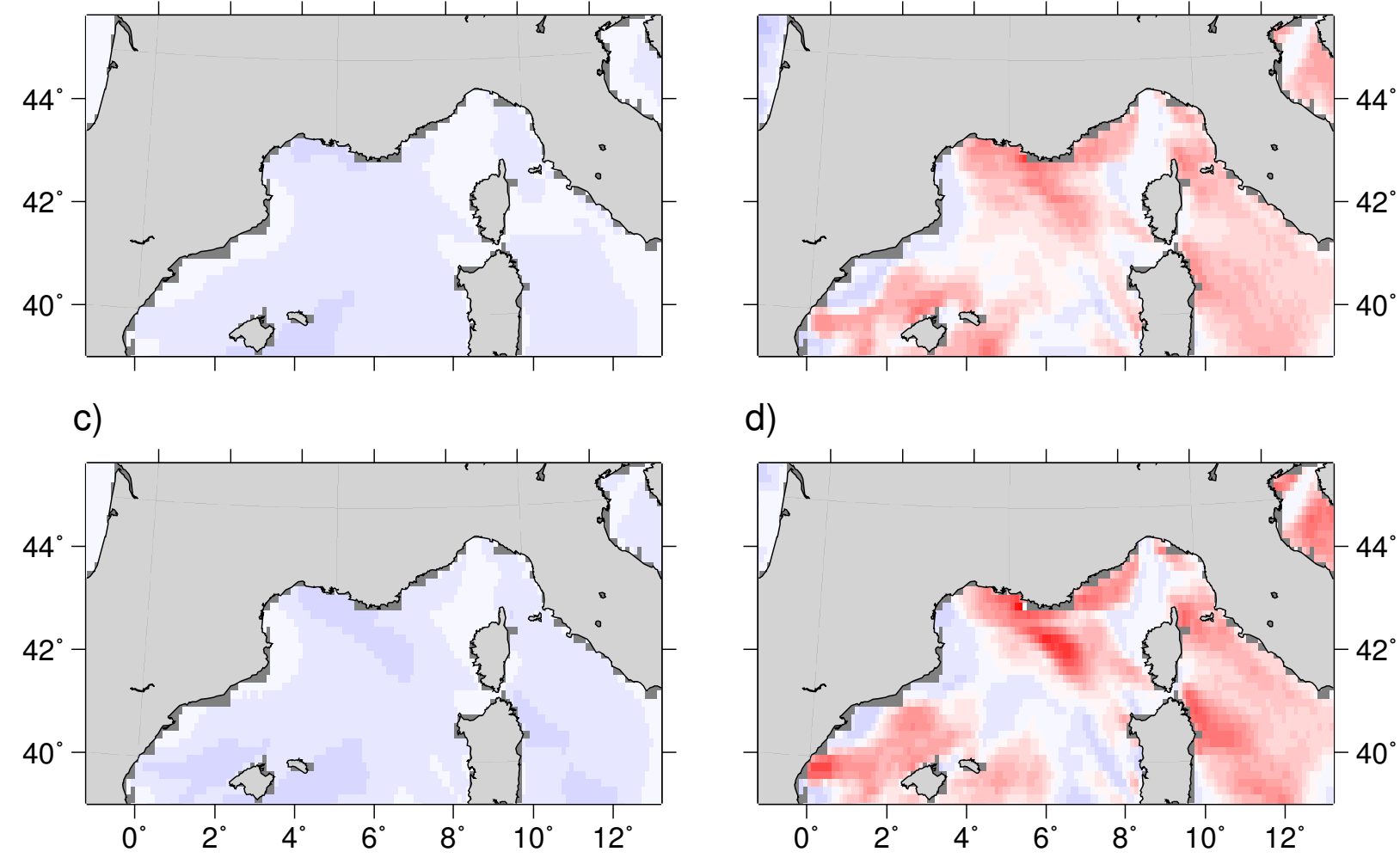

d)

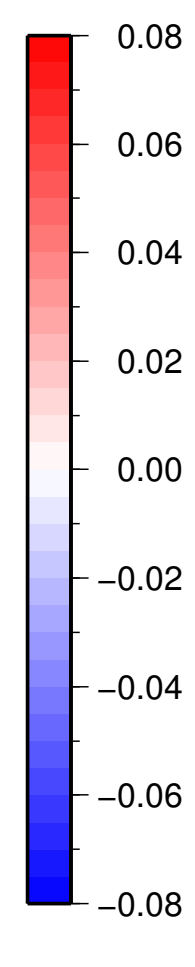

Figure 7. Friction velocity $\left(u_{*}, \mathrm{~m} \mathrm{~s}^{-1}\right)$ differences between WAV and NOWAV at 09 (a) and 12 UTC (c) on 26 October 2012, WAM and NOWAV at 09 (b) and 12 UTC (d). 
a)
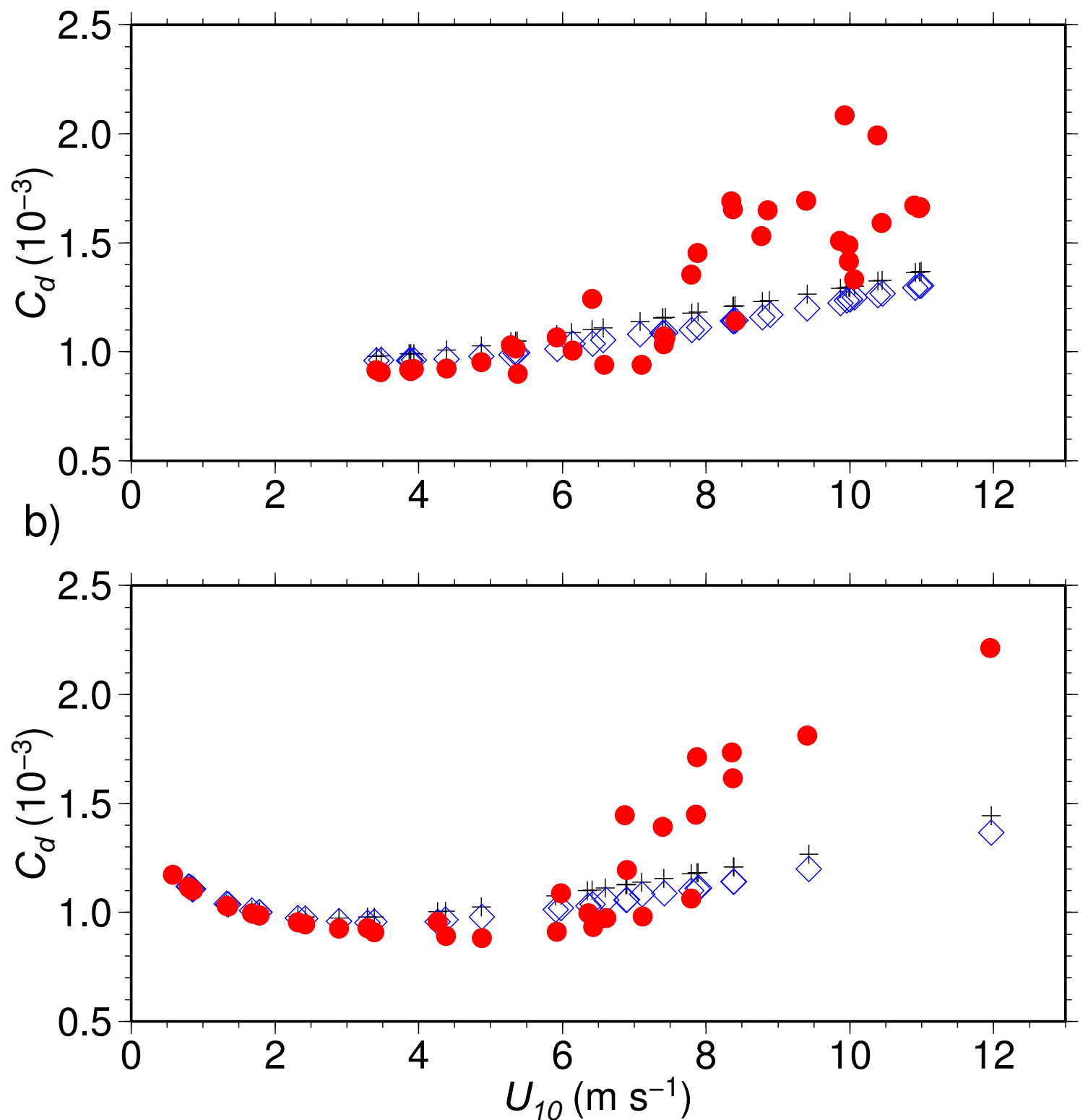

Figure 8. Evolution of the transfer coefficient $C_{d}$ associated to the momentum flux with the 10-m neutral wind speed at (a) the Lion and (b) Azur buoys for the three simulations: NOWAV (black plusses), WAV (blue diamonds) and WAM (red dots). 


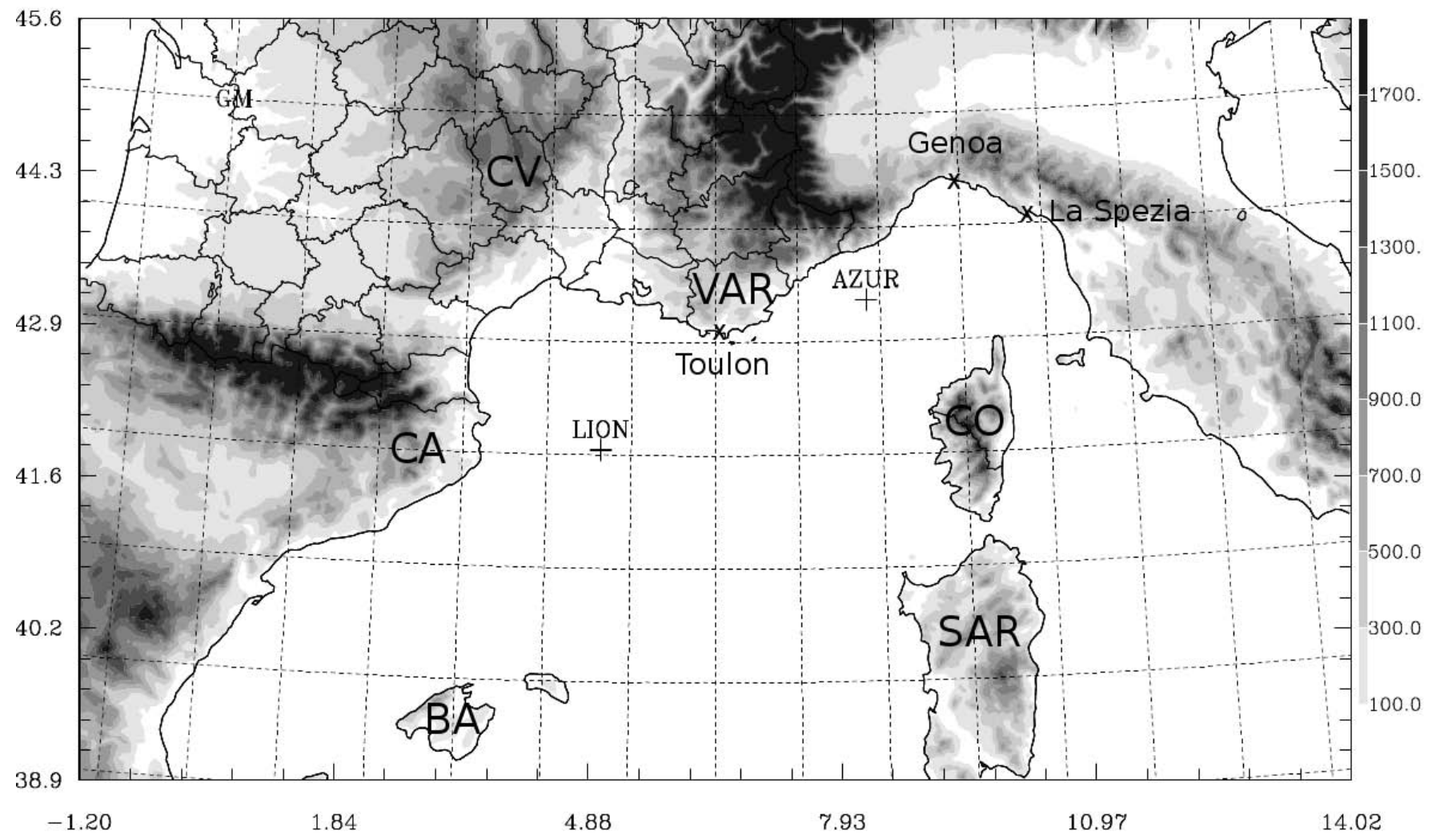

Figure 9. Domain used in the three $M E S O-N H$ simulations with some specific areas: CA, Catalonia; CV: Cévennes; CO, Corsica; SAR, Sardinia; BA, Balearic Islands; and VAR for the French Var department. 
a) 0630 UTC Observation

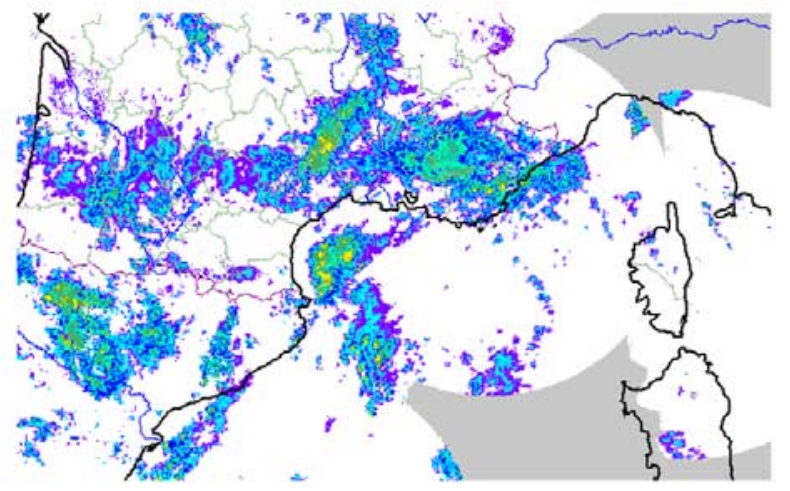

c) 0630 UTC NOWAV

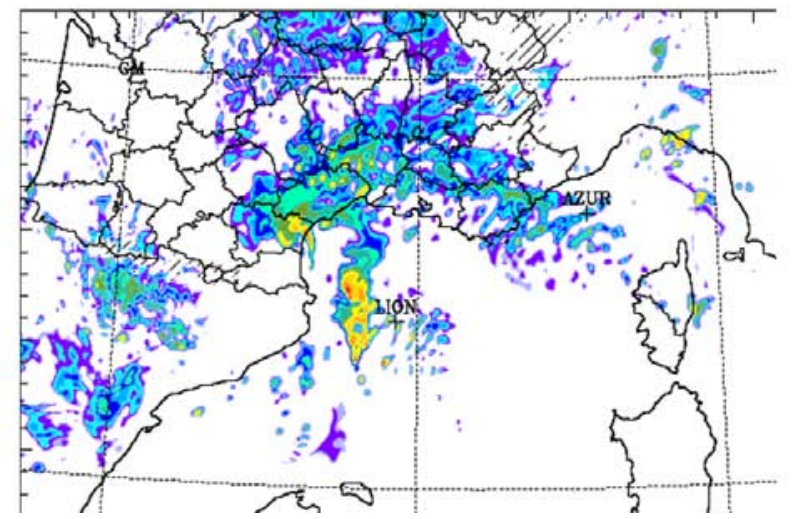

b) 12 UTC Observation

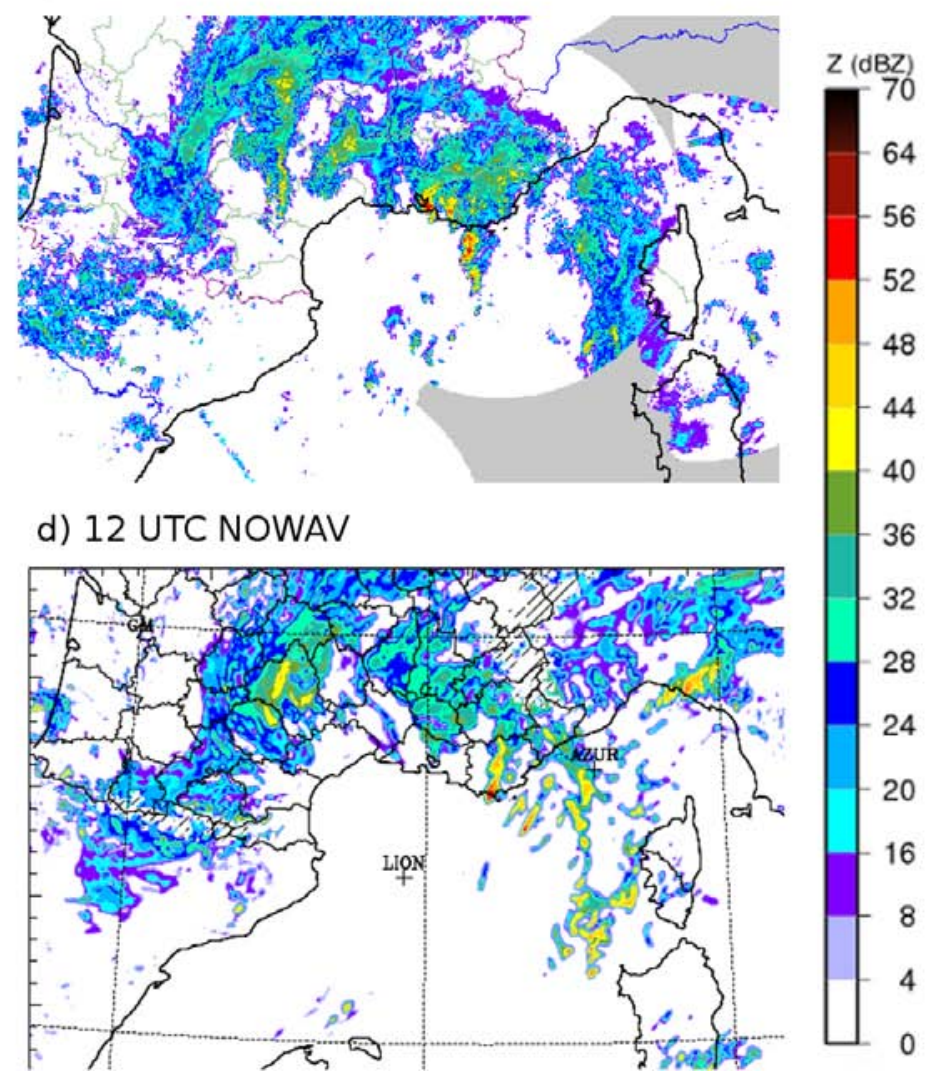

Figure 10. Radar reflectivities at 2000 m (dBZ): observed (top) versus simulated by NOWAV (bottom) at a) 0630 UTC and b) 12 UTC on 26 October 2012.

a) 06 UTC

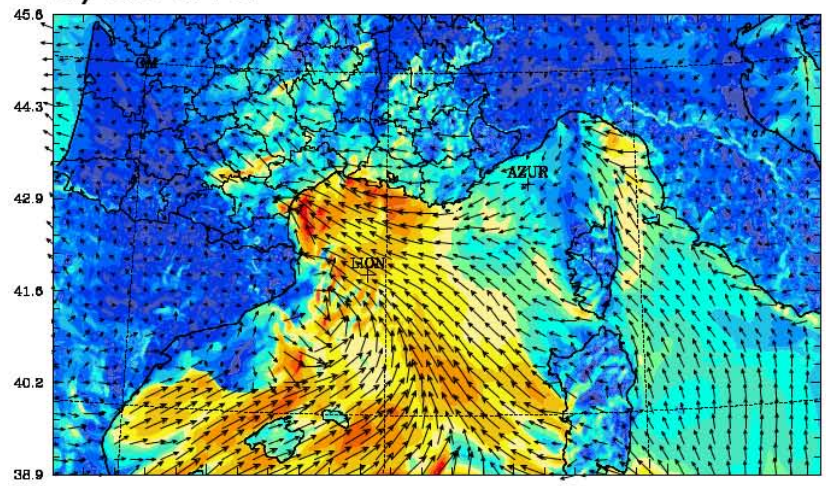

c) 12 UTC

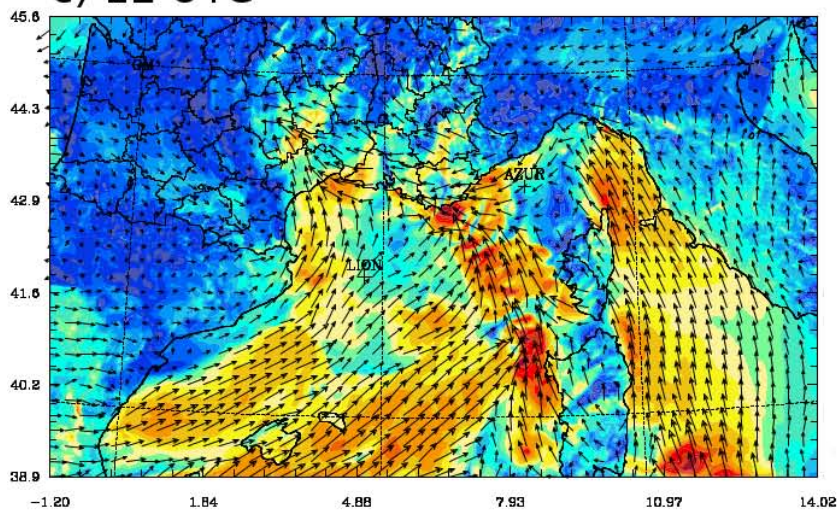

b) 08 UTC

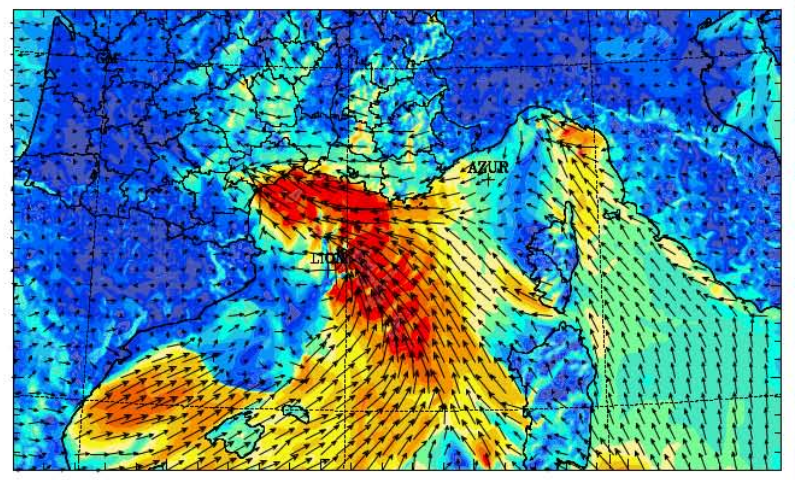

18.00
15.00
14.00
13.00
12.00
11.00
10.00
8.000

d) 16 UTC

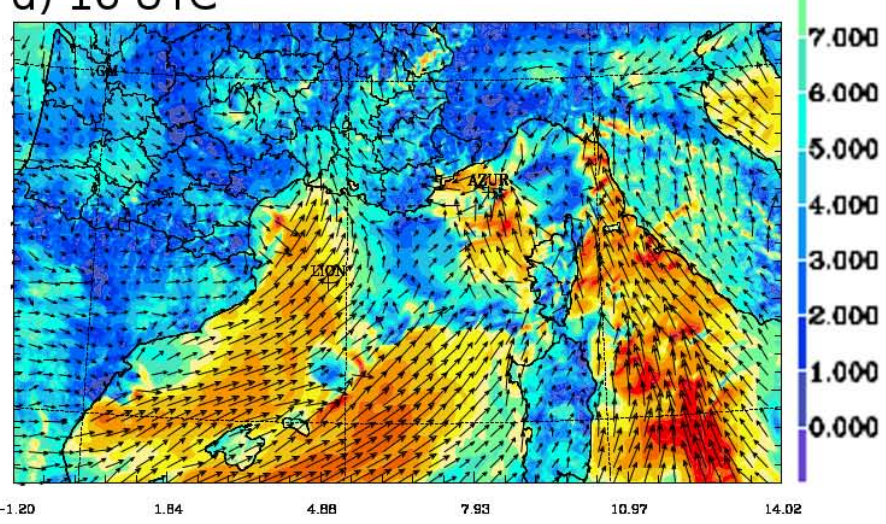




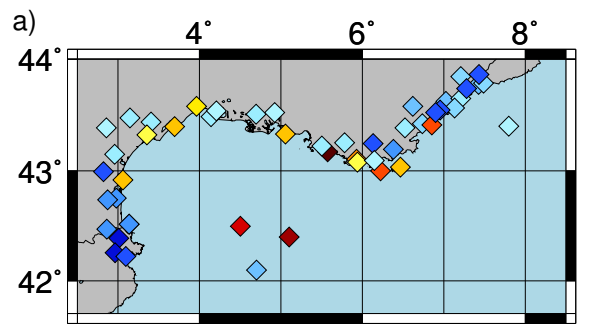

c)

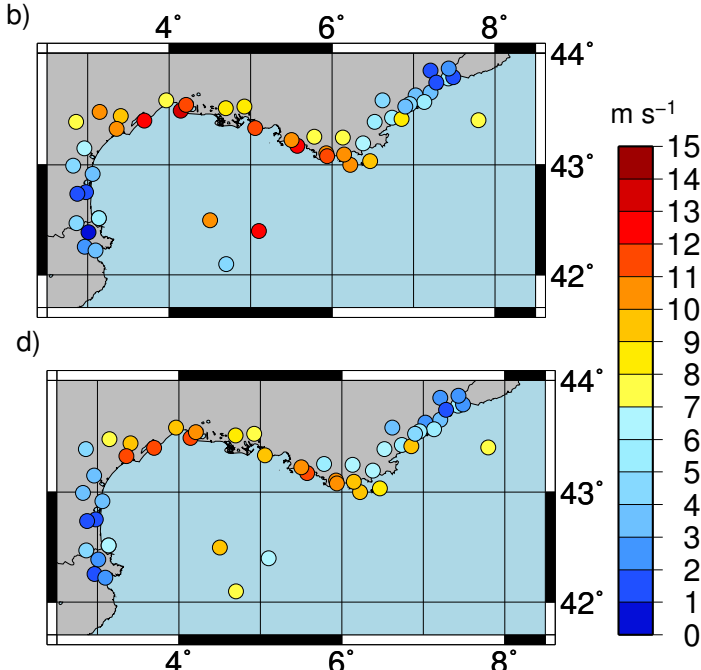

Figure 12. 10-m wind speed observed (a) and simulated by the NOWAV (b), WAV (c) and WAM (d) configurations at 09 UTC along the French coast.

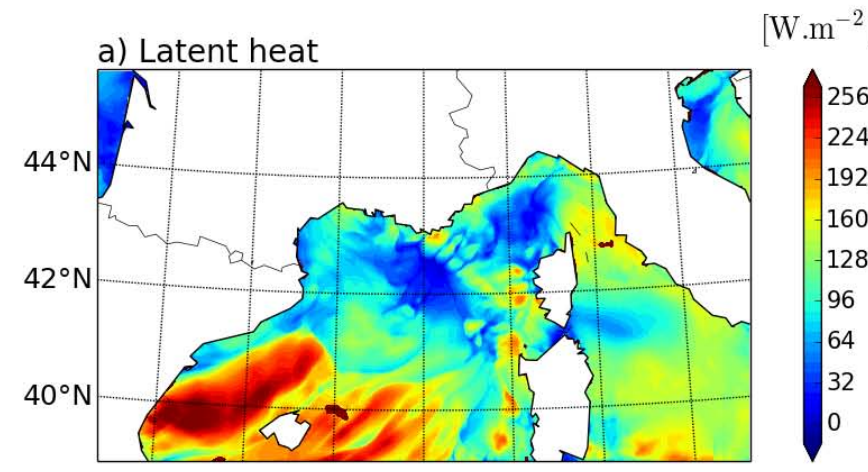

b) Relative humidity

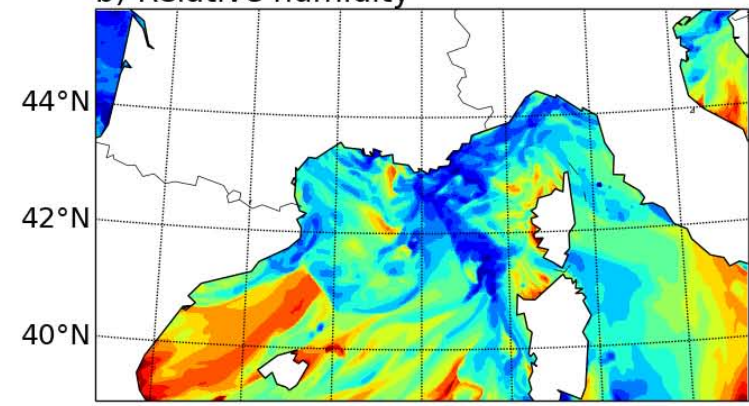

c) Momentum flux

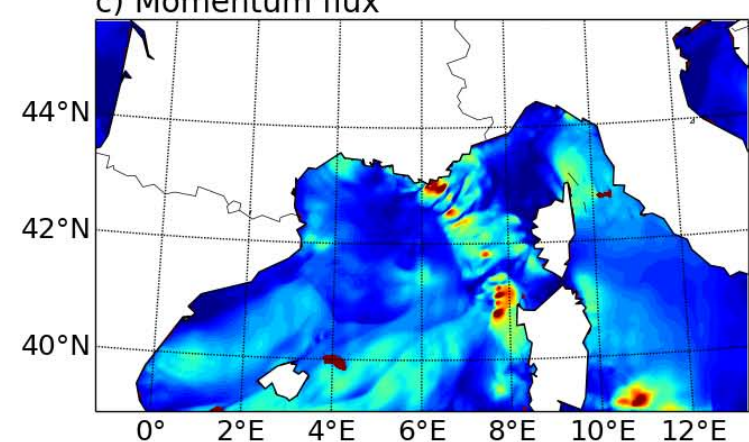

[\%]

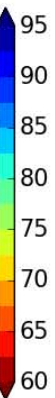

$\left[\mathrm{N} . \mathrm{m}^{-2}\right]$

0.600
0.525
0.450
0.375
0.300
0.225
0.150
0.075
0.000


a) Friction velocity

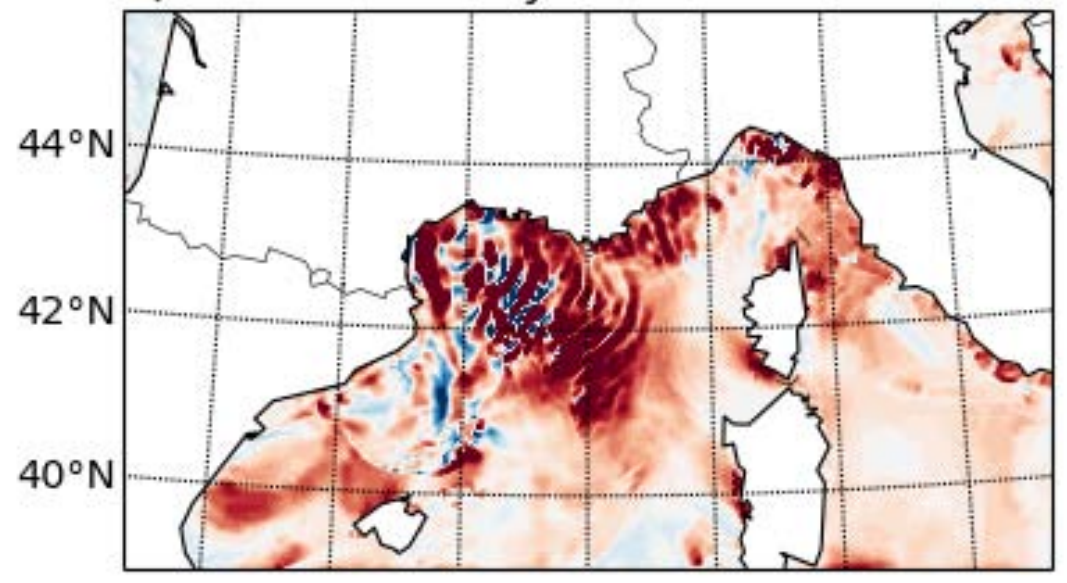

b) 10-m wind speed

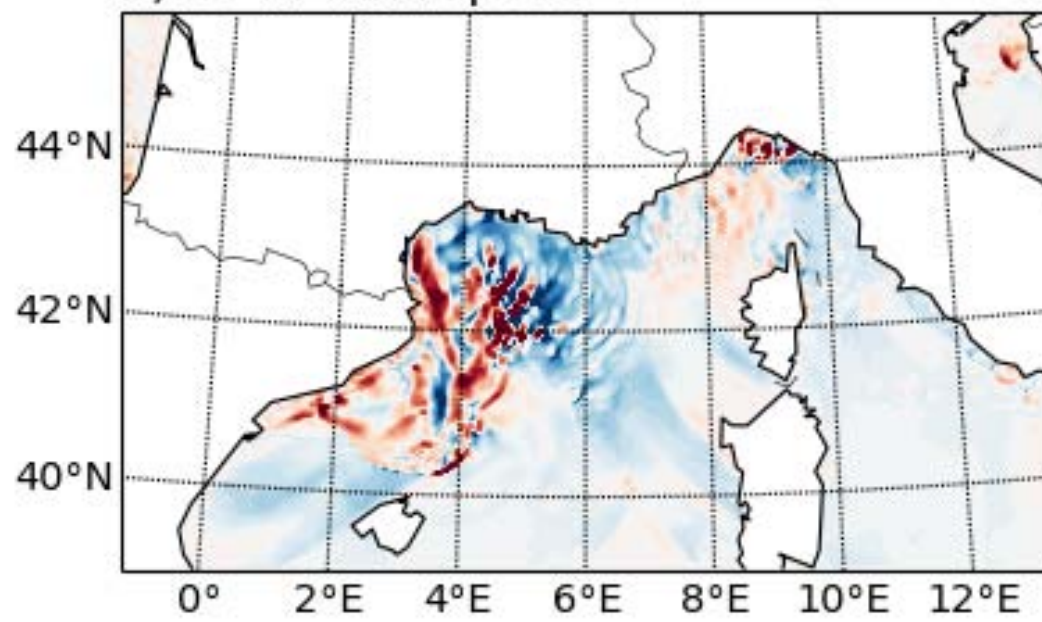

$\left[\mathrm{m} \mathrm{s}^{-1}\right]$

0.096

0.072

0.048

0.024

0.000

$-0.024$

$-0.048$

$-0.072$

$-0.096$

$\left[\mathrm{m} \mathrm{s}^{-1}\right]$

3.00

2.25

1.50

0.75

0.00

$-0.75$

$-1.50$

$-2.25$

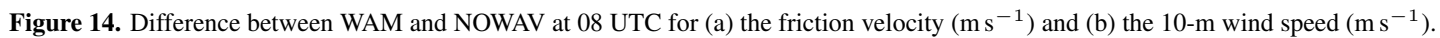



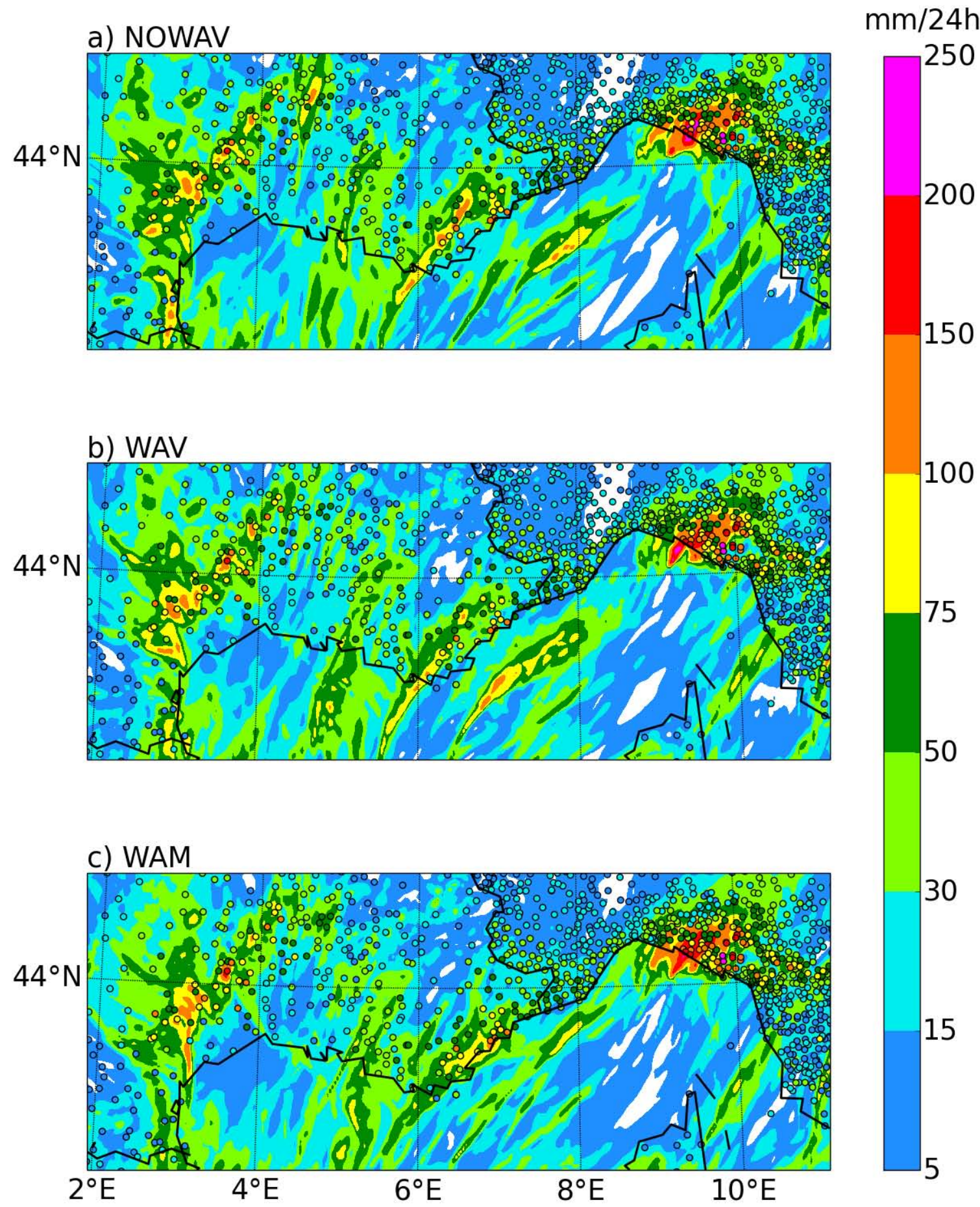

Figure 15. 24-h accumulated rainfall (mm) on 27 October 2012 at 00 UTC from (a) NOWAV, (b) WAV and (c) WAM. Coloured bullets are for the 24-h cumulative rainfall from rain gauge observations. 